\title{
AMBIENTES DE APRENDIZAGEM VIRTUAL COMO BASE FUNDAMENTAL NO TREINAMENTO COLABORATIVO ${ }^{1}$
}

\author{
VIRTUAL LEARNING ENVIRONMENTS AS A FUNDAMENTAL BASIS \\ IN COLLABORATIVE TRAINING ${ }^{1}$
}

\author{
Jairit Garavit ${ }^{2}$ \\ https://orcid.org/0000-0003-1976-9891
}

1. ¿Este produto é o resultado do trabalho árduo de uma de suas Linhas de Pesquisa do projeto "Como deve pesquisar em Educação virtual e a distância?" do ano de 2021, realizada com Membros de forma interdisciplinar e interinstitucional (Professores - Alunos) da Pesquisa Seedbed: Sistemas Integrados de Gestão "Integradoss" Anexados ao GrupLAC: SIGCIENTY da Universidade Nacional Aberta e a Distância UNAD.

2. Engenheiro Industrial, Especialista em Educação Superior e à Distância, Mestre em Sistemas Integrados de Gestão HSEQ-RSC, Revisor de Pares da Elsevier, Revisor de Pares da Publons Academy e Advisor \& Peer Rewiever de Mendeley, Editor de Currículo em Revistas Acadêmicas - Minciencias. Líder da Seedbed de Pesquisa "Integradoss" e nomeado Professor Pesquisador da Escola de Ciências Básicas, Tecnologias e Engenharia ECBTI. Zona Caribenha, na Universidade Nacional Aberta e a Distância - UNAD. Email institucional Jairit.Garavit@unad.edu.co

Projeto de Pesquisa: ¿Cómo pesquisar em Educação virtual e a distância? 
Resumo: Todos nós participamos e ajudamos na vida diária, tanto profissionalmente quanto privadamente, mas especificar esses elementos elucidativos de treinamento e ensino eficaz pode ser um desafio. O treinamento colaborativo, devido ao seu habitat restrito, requer notificação vigorosa para ocorrer. As declarações podem coincidir sem ajuda colaborativa? Poderíamos expressar esta questão expressando para todos que são um instrumento de formação eficaz, cada um deve lidar com o outro. Portanto, comunicação e colaboração são partes específicas do que criamos em nossas vidas diárias nas instituições educacionais, mas é difícil pensar sobre a profundidade de seu significado. Isso é equivalente e cobre uma diversidade de representações que podem ser classificadas em três conjuntos: Comunicação verbal, na qual você ouve um aluno para perceber seu significado, comunicação escrita, na qual você estuda seu significado. Comunicação não verbal, é aquela que dá atenção a uma pessoa e deduz o seu significado. Colaboração, indistintamente, é uma expressão desenvolvida; cujas unidades se encontram em várias genealogias, o argumento-chave não é tanto sobre nós ou as penetrações das zonas de classificação, mas como as usamos para ter uma marca positiva sobre a eficácia do treinamento e ensino em nosso treinamento.

Palavras chaves: Comunicação Colaborativa, Ambientes de Aprendizagem, Colaboração Educacional, Ambientes Virtuais.

Abstract: We all participate and assist in daily life, both professionally and privately, but specifying these elucidative elements of training and effective teaching can be a challenge. Collaborative training, due to its tight habitat, requires vigorous notification to take place. Can the declarations be submitted without collaborative assistance? We could express this question by expressing that for anyone to be an effective training instrument, each one must deal with one another. Therefore, Communication and collaboration are specific parts of what we create in our daily lives in educational institutions, and yet it is hard to think about the depth of their meaning. This is equivalent, and covers a diversity of representations that can be classified into three sets: Verbal communication, in which you listen to a student to perceive their meaning, written communication, in which you study their meaning. Nonverbal communication, is the one to pay attention to a person and deduce its meaning. Collaboration, indistinctly, is a developed expression; whose units meet in various genealogies, the key argument is not so much about us or the penetrations of the classification areas, but how we use them to have a positive mark on the effectiveness of training and teaching in our training.

Keywords: Collaborative Communication, Learning Environments, Educational Collaboration, Virtual Environments. 


\section{Introdução}

As distinções formadas nos capítulos anteriores entre aprendizagem cooperativa e colaborativa mostram que a abordagem colaborativa é adequada para alunos que sabem demonstrar autonomia e que desejam participar voluntariamente de um processo que combina trabalho individual e coletivo. Vimos também que esta abordagem é baseada em ambientes ricos onde o aluno encontra os recursos e ferramentas necessários para realizar atividades individuais e em grupo.

Em um contexto de ensino à distância, a colaboração entre os alunos é possível graças aos ambientes de tecnologia acessíveis remotamente. As áreas comuns de compartilhamento de recursos, espaços de comunicação em grupo e o espaço privado existem para facilitar a colaboração. É através deles que se desenvolve a colaboração. Aprendendo apenas em um espaço privado, engaja-se em um diálogo interno para construir novos conhecimentos; Em grupo, no espaço de comunicação, ele troca com os colegas para dar continuidade à construção do conhecimento, para discuti-lo e validá-lo. No espaço comum, encontre todos os instrumentos necessários à realização do trabalho atribuído que conduza à concretização do objetivo que o grupo traçou.

Este capítulo trata de ambientes virtuais de aprendizagem que remetem a uma pedagogia aberta de acordo com os valores do construtivismo. Descrevemos os espaços colaborativos que estruturam esses ambientes antes de estudar mais especificamente aquele reservado à comunicação em grupo.

Mostramos como, neste espaço, a pedagogia colaborativa explora o fórum eletrônico e a interação escrita como recursos privilegiados de aprendizagem. Então veremos que o fórum está localizado no coração dos ambientes virtuais de aprendizagem e que oferece lugares para trocar e compartilhar onde ocorre a parte mais importante da colaboração e interação. Também veremos quais condições devem ser atendidas para que uma colaboração baseada na interação por escrito seja bem-sucedida. Acabamos propondo aos designers de ambientes virtuais de aprendizagem a criação de fóruns eletrônicos em locais de teletrabalho, telegestão, tele-discussão e tele-assistência para fiscalizar o trabalho colaborativo.

\section{Ambientes de treinamento e aprendizagem}

A noção de um ambiente de aprendizagem não é nova; tem sido explorado pela corrente da pedagogia aberta que vê a escola como um ambiente fragmentado. Durante 1970, várias aplicações desta pedagogia viram o dia. A escola aberta já não se organiza por grupos de turmas, mas em espaços com finalidades diversas e dentro dos quais existem vários recursos: um recanto de história e geografia, outro de matemática, outro de desenho e artesanato., Etc. 
A escola torna-se um local diáfano onde alunos de diferentes turmas acessam esses espaços e recursos de acordo com um horário flexível e variável para a realização de trabalhos individuais e em equipe (Morlan, 1973). As turmas ainda possuem uma sede onde se reúnem para receber explicações e instruções, planejar e organizar o trabalho e fazer um balanço de sua aprendizagem com o professor. Este último, que não é mais a única fonte de conhecimento, não é mais um facilitador que oferece suporte didático e para quem a aprendizagem resulta da descoberta guiada.

Para nós, ambientes virtuais de aprendizagem são vistos um pouco como escolas abertas e desagregadas, mas sem conhecer os graves problemas de planejamento, gestão e acesso aos recursos do espaço físico que a escola aberta conheceu. Graças às tecnologias, agora é possível criar mais facilmente ambientes abertos onde se encontram todos os espaços desejados, abundantes em recursos e acessíveis a todos sem limitações de tempo e espaço.

Hoje, as comunidades de educação, formação e desenvolvimento no local de trabalho estão se voltando para ambientes virtuais de aprendizagem na esperança de encontrar uma resposta promissora à demanda urgente de modelos de aprendizagem adaptáveis a diferentes perfis de aprendizagem e suficientemente flexíveis. Para superar as limitações de tempo, espaço, acesso aos recursos. Mas antes que os ambientes virtuais de aprendizagem possam se estabelecer e se espalhar nesses ambientes, ainda há um longo processo de apropriação a ser feito e pelo menos três grandes desafios a serem enfrentados:

- Adote uma mudança educacional radical que nos leve a fazer do aprendizado o nosso principal problema, em vez de focar no ensino como uma prioridade.

- Adoptar novos métodos de desenho pedagógico adaptados à concepção dos tipos de ambientes.

- Domine novos conhecimentos tecnológicos para criar ambientes amigáveis que sejam fáceis de distribuir, manter e gerenciar.

\section{EVA - Ambientes Virtuais de Aprendizagem}

Para muitos, o termo "ambiente virtual de aprendizagem" refere-se cada vez mais a universos dinâmicos intimamente associados a uma visão construtivista, cujo funcionamento é essencialmente caracterizado pela interação humana. Outros ainda os vêem como produtos estáticos construídos pela montagem de objetos tecnológicos usados apenas para transmitir informações. Optamos pela primeira compreensão e usamos os termos de Bordeleau (1994) que descrevem ambientes de aprendizagem informatizados, lembrando as escolhas pedagógicas subjacentes e seus componentes tecnológicos. 
Uma organização espaço-temporal real ou virtual composta por um conjunto de elementos interativos, mundanos ou imaginários, bem como pessoas, máquinas, software, técnicas e condições que podem atuar sobre as atividades humanas. Ao classificar o ambiente de aprendizagem, significa que, entre as atividades humanas, as de aprender e de aprender a aprender devem predominar. Por agregar tecnologia, queremos dizer que, entre os elementos que interagem, é obrigatória a presença de máquinas, softwares, técnicas e recursos humanos que se apropriaram deles. Lembre-se de que a tecnologia deve ser entendida tanto como objetos técnicos (materiais, máquinas, ferramentas, programas, software) quanto como processos de design. produção ou uso de tais objetos. No campo que nos ocupa,

Completamos esta definição adicionando a noção de um sistema proposto por Doré e Basque (1998). Na perspectiva da teoria de sistemas, o ambiente abriga um ou mais sistemas e subsistemas. É um conjunto organizado de componentes em interação cujas ações contribuem para atingir um objetivo. Portanto, em um ambiente de aprendizagem real ou virtual, o treinador, o aluno, o grupo, a aula, os manuais e outros recursos são subsistemas em interação orientados para o desenvolvimento de novos conhecimentos. Doré e Basque também colocam esses sistemas de aprendizagem no paradigma construtivista porque se baseiam na exploração do conhecimento, na iniciativa pessoal e na liberdade de escolha.

Portanto, ambientes são sistemas projetados para apoiar comunidades de alunos que desejam colaborar. Eles fornecem locais onde os alunos interagem e trabalham usando uma variedade de recursos. Devido ao grau de liberdade permitido em um ambiente de aprendizagem, o processo de aprendizagem não é ditado pela autoridade de um treinador. Antes, é oferecido ao aluno e ao grupo, depois discutido e negociado com o objetivo de criar um consenso quanto ao objetivo a ser alcançado e para que as expectativas e responsabilidades de cada um sejam atendidas.

O papel do treinador passa a ser o de guia. Em suma, sob o conceito de ambiente, o esquema de ambientes virtuais de aprendizagem é baseado no construtivismo e utiliza tecnologia, é uma tarefa complexa que coloca dois problemas principais para designers (Doré e Basque, 1998). O primeiro problema diz respeito à natureza difusa dos ambientes que devem ser capazes de se adaptar às contingências dos procedimentos livres e às necessidades específicas de cada grupo. Para resolver este problema, os esforços dos designers não devem mais centrar-se na definição de estratégias pedagógicas, mas na antecipação dos processos de aprendizagem, nas necessidades dos alunos e no acesso às ferramentas e recursos que serão utilizados.

O segundo problema é a falta de métodos adequados de design instrucional e a falta de conhecimento pragmático para criar esses ambientes. Deve-se lembrar que o design ou design educacional se destina a ser um processo científico que visa encontrar e aplicar meios para promover a formação. O resultado é um conjunto contíguo de planos e especificações que 
descrevem as atividades de aprendizagem e ensino. Apoiando-se em fundamentos teóricos sólidos, os métodos de design instrucional oferecem intervenções instrucionais consistentes com as teorias de aprendizagem nas quais se baseiam. No entanto, aqueles que são de uso comum há muitos anos, por exemplo, os de Mager, 1962, Briggs (1981), não podem levar em conta as novas teorias de aprendizagem. dos avanços nas ciências cognitivas. Eles também não atendem aos requisitos de design de ambientes de aprendizagem mediados e informatizados. Mais precisamente, não permitem tirar partido da natureza interactiva e do potencial mediático das tecnologias (nem têm em conta a complexidade da situação de aprendizagem que envolve e interage com vários actores e múltiplos recursos).

Os métodos tradicionais de design instrucional concentram-se na análise cuidadosa do problema de treinamento. Eles adotam abordagens de desenvolvimento sequencial, em estágios e de loop de feedback para produzir, de maneira sistemática e planejada, um produto de treinamento acabado.

O design de ambientes de aprendizagem virtuais dinâmicos não pode mais acomodar esses métodos. Devem ser desenvolvidas novas práticas de design pedagógico capazes de operacionalizar e integrar elementos teóricos de sistemas e cognitivismo, explorando plenamente o potencial das tecnologias. Os pesquisadores estão atualmente trabalhando para desenvolver fundamentos teóricos, ferramentas metodológicas e ferramentas de software ou sistemas para compensar as deficiências dos designers de ambientes de aprendizagem.

\section{Construção de ambientes de treinamento}

Os avanços nas ciências cognitivas para decodificar os mecanismos de aprendizagem, os avanços nas tecnologias de comunicação (multimídia, hipertexto, hipermídia, serviços telemáticos, etc.) e a ascensão da Internet como meio de disseminação colocaram o designer de ambientes de comunicação. de possibilidades. No centro, na equipa de investigação, os investigadores destacaram a multiplicidade de decisões que devem ser tomadas para conceber este tipo de ambiente e quiseram satisfazer as necessidades dos designers através do desenvolvimento de um método e ferramentas para a engenharia educacional. Eles desenvolveram o MISA, Método para Sistemas de Aprendizagem de Engenharia, que leva em consideração a complexidade dos sistemas de aprendizagem.

Ousadamente construtivista, o MISA usa a técnica de modelagem de objetos tipificados (MOT) para representar sistemas de aprendizagem. Conforme mostrado na Tabela 2.1, este método prossegue em seis fases:

- Definição do projeto de formação, princípios norteadores da formação.

- Análise preliminar. 
- Arquitetura do sistema de aprendizagem.

- Elaboração de orçamentos para materiais didáticos.

- Produção de equipamentos e ambientes com base em orçamentos.

- Planejamento de disseminação.

Em cada uma dessas fases, o método aborda o problema de design ao longo de quatro eixos:

- O eixo de conhecimentos e habilidades a adquirir.

- O eixo educacional.

- O eixo da mídia,

- O eixo de difusão.

Embora estruturado em fases, em eixos para a realização de tarefas e atividades, o MISA não oferece necessariamente uma abordagem linear; usa um processo de resolução de problemas de projeto usando uma abordagem em espiral e iterações sucessivas.

A tabela a seguir fornece uma visão geral das fases e eixos do MISA. 
Tabela 2.1

Fases e Eixos da Massa

\begin{tabular}{|c|c|c|c|c|c|c|c|}
\hline $\begin{array}{c}\text { Frase 1 } \\
\text { definição do } \\
\text { projeto } \\
\text { Treinamento }\end{array}$ & & & $\begin{array}{c}\text { Fase } 2 \\
\text { Análise } \\
\text { preliminar. }\end{array}$ & $\begin{array}{c}\text { Fase } 3 \\
\text { Arquitetura }\end{array}$ & $\begin{array}{c}\text { Fase } 4 \\
\text { Orçamentos } \\
\text { de materiais } \\
\text { e tele } \\
\text { serviços. }\end{array}$ & $\begin{array}{c}\text { Fase } 5 \\
\text { Realização e } \\
\text { validação. }\end{array}$ & $\begin{array}{c}\text { Fase } 6 \\
\text { Plano de } \\
\text { disseminaçãa } \\
0\end{array}$ \\
\hline \multirow{4}{*}{ 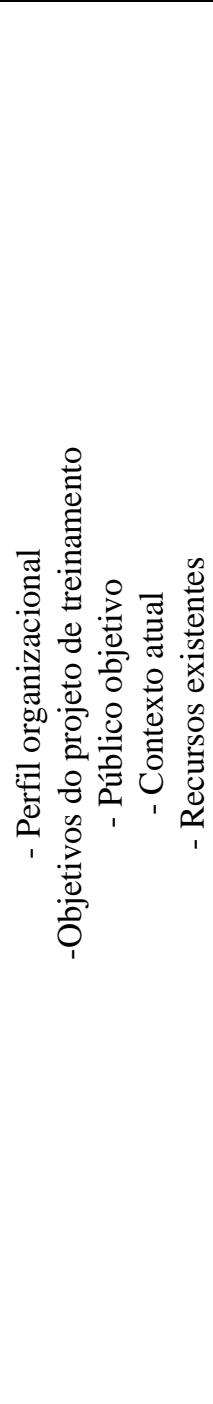 } & \multirow{4}{*}{ O্= } & $\begin{array}{c}\text { Modelo de } \\
\text { conhecime } \\
\text { nto. }\end{array}$ & $\begin{array}{c}\text { Descreva o } \\
\text { modelo de } \\
\text { conheciment } \\
\text { o e a tabela } \\
\text { de } \\
\text { habilidades. }\end{array}$ & $\begin{array}{c}\text { Preencha o } \\
\text { modelo de } \\
\text { conheciment } \\
\text { o e a tabela } \\
\text { de } \\
\text { habilidades. }\end{array}$ & $\begin{array}{c}\text { Descreva os } \\
\text { submodelos } \\
\text { associados a } \\
\text { instrumentos } \\
\text { e objetos } \\
\text { materiais. }\end{array}$ & \multirow[b]{2}{*}{$\begin{array}{c}\text { Material } \\
\text { educacional }\end{array}$} & $\begin{array}{c}\text { Descreva a } \\
\text { gestão do } \\
\text { conheciment } \\
\text { o. }\end{array}$ \\
\hline & & $\begin{array}{c}\text { Modelo } \\
\text { educaciona } \\
1 .\end{array}$ & $\begin{array}{l}\text { Descreva a } \\
\text { rede de } \\
\text { eventos de } \\
\text { aprendizage } \\
\mathrm{m} .\end{array}$ & $\begin{array}{l}\text { Complete a } \\
\text { rede de } \\
\text { eventos de } \\
\text { aprendizage } \\
\text { m. } \\
\text { Descreva os } \\
\text { ambientes } \\
\text { educacionais }\end{array}$ & $\begin{array}{c}\text { Defina as } \\
\text { propriedades } \\
\text { dos } \\
\text { instrumentos } \\
\text { e objetos } \\
\text { materiais. }\end{array}$ & & $\begin{array}{l}\text { Descreva a } \\
\text { gestão de } \\
\text { alunos e } \\
\text { facilitadores. }\end{array}$ \\
\hline & & $\begin{array}{l}\text { Modelo de } \\
\text { mídia. }\end{array}$ & $\begin{array}{c}\text { Oriente o } \\
\text { modelo de } \\
\text { material. }\end{array}$ & $\begin{array}{c}\text { Descreva a } \\
\text { infraestrutur } \\
\text { a de } \\
\text { engenharia. } \\
\text { Guie o } \\
\text { modelo de } \\
\text { mídia. }\end{array}$ & $\begin{array}{c}\text { Descreva os } \\
\text { modelos de } \\
\text { materiais e } \\
\text { ferramentas e } \\
\text { meios de } \\
\text { comunicação. } \\
\text { Definir } \\
\text { serviços e } \\
\text { ambientes de } \\
\text { treinamento. }\end{array}$ & $\begin{array}{c}\text { Produzir } \\
\text { material } \\
\text { educacional. } \\
\text { Faça o log de } \\
\text { alterações. }\end{array}$ & $\begin{array}{c}\text { Descreva a } \\
\text { gestão do } \\
\text { SA, } \\
\text { materiais e } \\
\text { recursos. }\end{array}$ \\
\hline & & $\begin{array}{l}\text { Modelo de } \\
\text { difusão. }\end{array}$ & $\begin{array}{c}\text { Orientar o } \\
\text { modelo de } \\
\text { distribuição. } \\
\text { Conduza uma } \\
\text { análise } \\
\text { preliminar de } \\
\text { custo- } \\
\text { benefício- } \\
\text { impacto. }\end{array}$ & $\begin{array}{c}\text { Orientar o } \\
\text { modelo de } \\
\text { distribuiçãa. }\end{array}$ & $\begin{array}{c}\text { Descreva o } \\
\text { modelo de } \\
\text { distribuição, } \\
\text { infraestrutura } \\
\text { organizaciona } \\
\text { le } \\
\text { tecnológica. }\end{array}$ & $\begin{array}{c}\text { Estabeleça o } \\
\text { teste e o } \\
\text { plano de } \\
\text { teste. } \\
\text { Defina o log } \\
\text { de alterações. }\end{array}$ & $\begin{array}{c}\text { Descreva o } \\
\text { gerenciamen } \\
\text { to da } \\
\text { qualidade. }\end{array}$ \\
\hline
\end{tabular}

Garavit, J. 2021.

As equipes de pesquisa do UNICEF também desenvolveram um modelo de campus virtual (Figura 2.1) totalmente dedicado ao ensino à distância, organizado em torno de cinco atores:

- O Aprendiz.

- O designer.

- O treinador. 
- O diretor de treinamento.

- O especialista em conteúdo.

Cada um desses atores está envolvido em vários processos:

- Um processo de aprendizagem.

- Um processo de design.

- Um processo de mentoria.

- Um processo de gestão.

- Um processo de informação.

Figura 2.1

Processo e atores do campus virtual

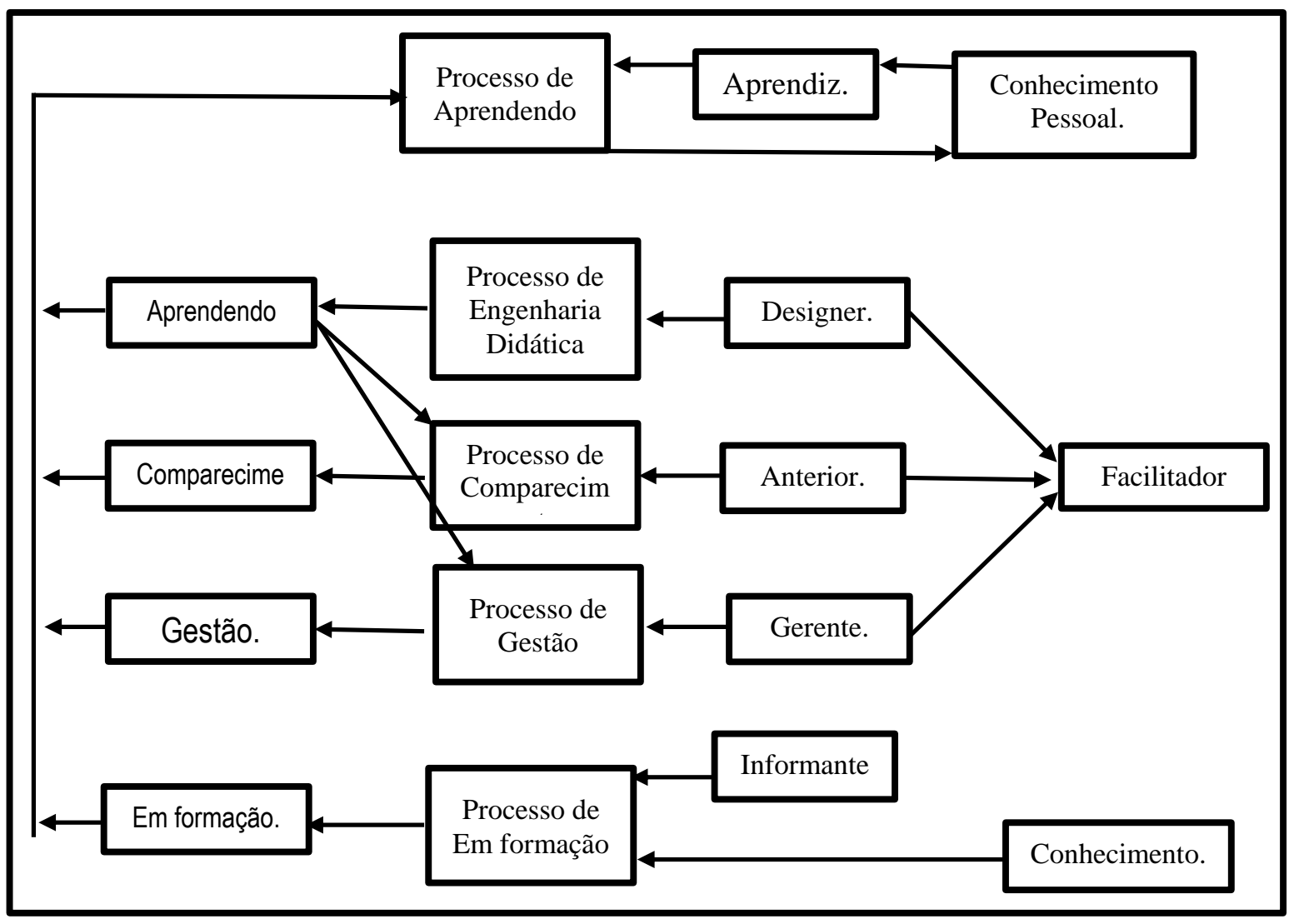

Garavit, J. 2021

Os recursos do campus virtual estão divididos em cinco espaços (figura 2.2): o espaço de autogestão permite que os alunos planejem, gerenciem e supervisionem sua aprendizagem, o espaço de informação agrupa documentos de todos os tipos, o espaço de produção contém os elementos necessários para realizar a tarefa de formar e produzir o trabalho esperado, o 
espaço de colaboração reúne ferramentas e oferece locais que permitem ao aluno trocar opiniões e participar de trabalhos em grupo ou em equipe; a área de suporte fornece ajuda e aconselhamento de uma pessoa de recursos online ou sistema de computador.

Esta arquitetura genérica, disponível para designers, serve como uma estrutura conceitual para projetar ambientes virtuais de aprendizagem, enquanto o MISA fornece um método para desenvolver tais ambientes.

Figura 2.2

Cinco áreas do campus virtual

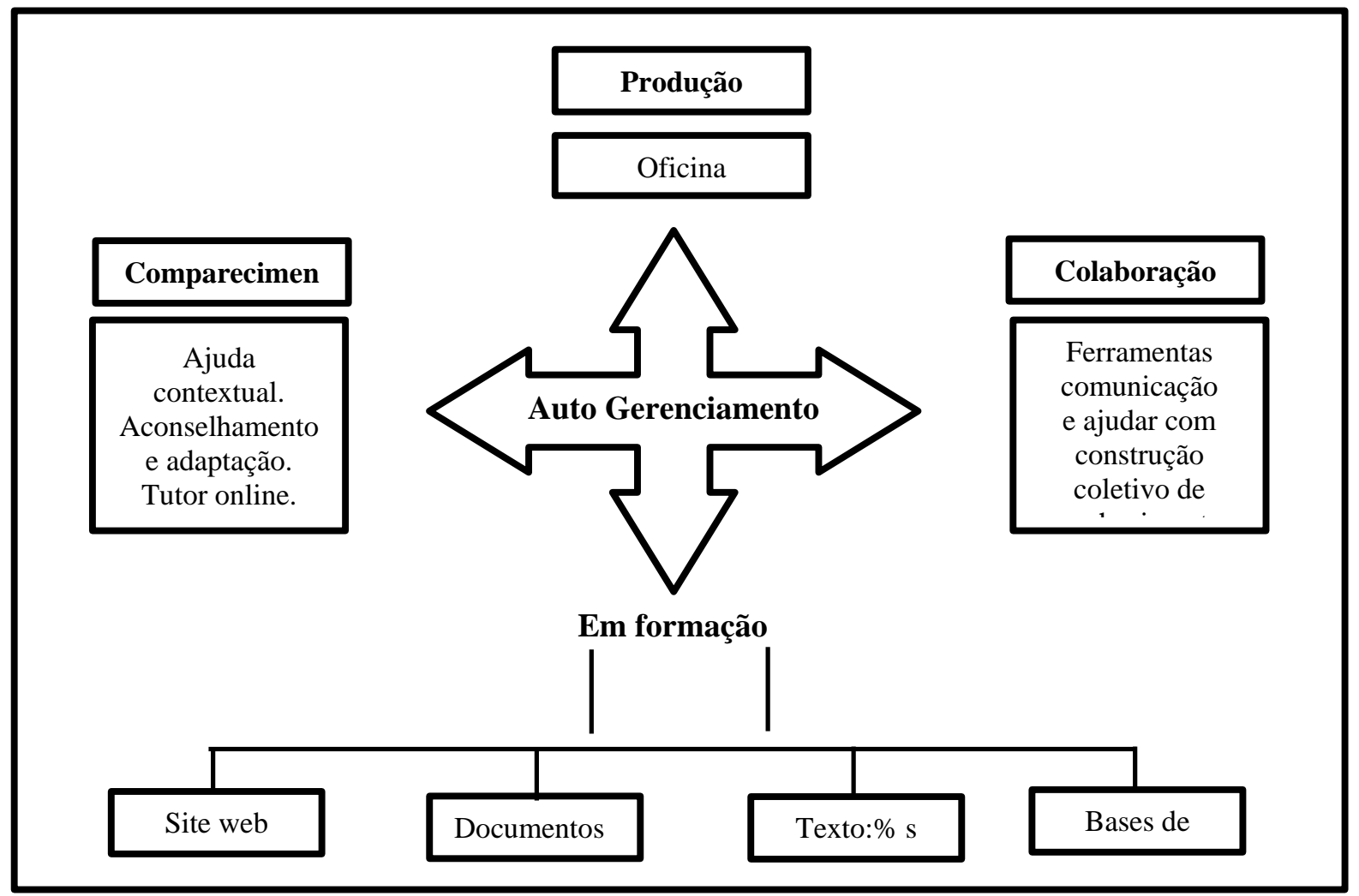

Garavit, J. 2021

Para os fins deste estudo, nos concentramos em modelar o espaço de colaboração sabendo que, em um ambiente de aprendizagem plena, os demais espaços de um campus virtual devem estar presentes.

\section{Área de colaboração e treinamento}

A colaboração, seja qual for sua natureza, propósito ou objeto, precisa de espaços para existir. Neste caso, o espaço pode corresponder a um local físico ou virtual onde os alunos se encontram para trabalhar juntos. Este termo também pode receber um valor metafórico para abranger universos de ideias, sentimentos e emoções compartilhados pelo grupo. Em 
um sentido concreto, o espaço de colaboração pode, portanto, ser uma sala de reunião onde os colaboradores discutem o projeto que os aproxima, ou um laboratório onde pesquisadores trabalham para avançar um projeto comum. Mas também podem ser algumas folhas de papel nas quais foram rabiscadas notas durante uma conversa informal ou um modelo, conceito ou hipótese desenvolvida por um dos colaboradores e apresentada ao grupo. Em resumo, O espaço de colaboração é qualquer entidade que o grupo possa compartilhar e que permita processar, traduzir ou relatar representações desenvolvidas individualmente ou em grupos. Para os funcionários, esses espaços são recursos ou ferramentas que transmitem cognição. Eles são verdadeiros parceiros colaborativos (Schrage, 1990).

Figura 2.3

\section{Áreas e ferramentas de colaboração}

\section{Ambiente de Colaboração Virtual}

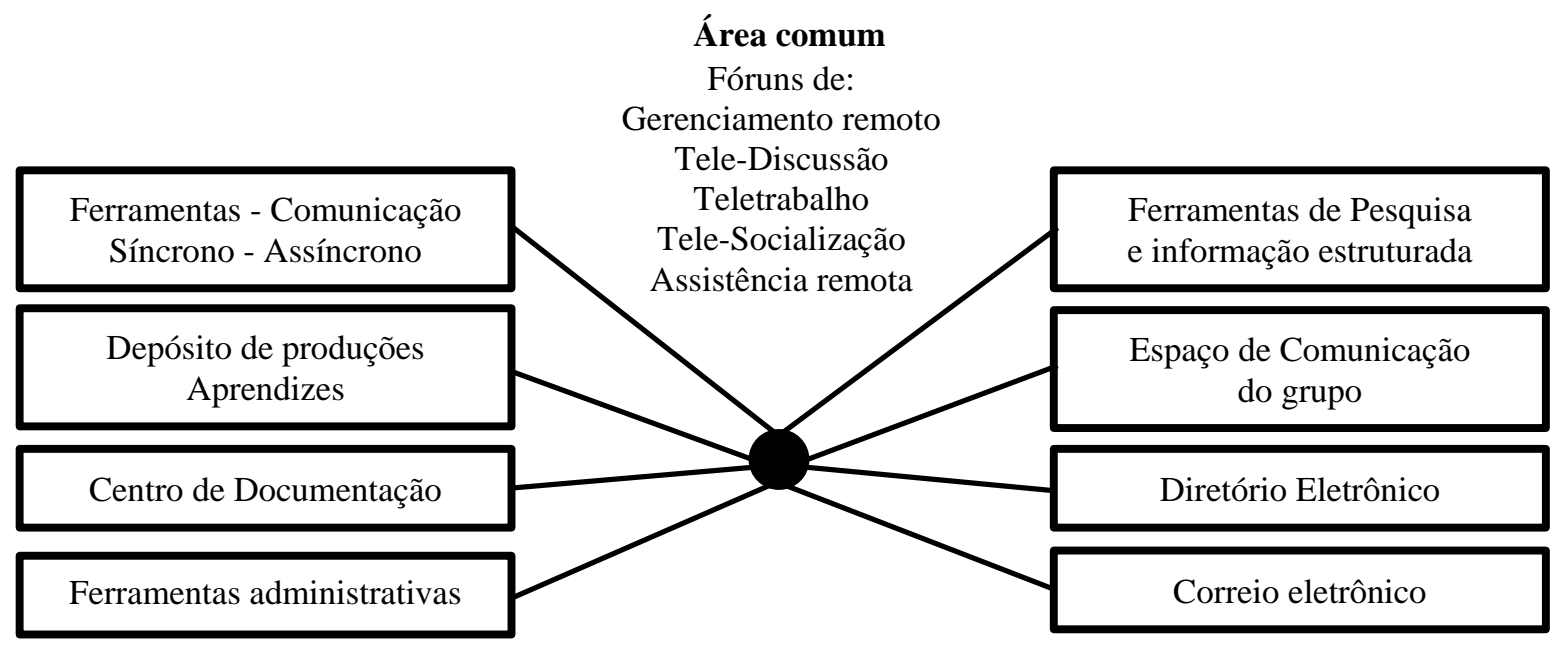

\section{Espaço privado}

Agendas.

Ferramenta de tomada de notas.

Ferramenta de estruturação da informação.

Ferramentas de produção.

\section{Garavit, J. 2021}

Os designers de ambientes de aprendizagem podem planejar, configurar e organizar espaços de colaboração específicos. Outros se organizam em colaboração, como universos intelectuais, culturais, sociais ou emocionais que são emanações mais ou menos espontâneas do grupo que o designer dificilmente pode prever e planejar. Para fins de design educacional de ambientes virtuais de aprendizagem, sugerimos que os designers forneçam três amplos espaços básicos para colaboração (ver figura 2.3): 
- A área privada,

- A área comum,

- O espaço de comunicação

\section{O espaço privado: um centro de aprendizagem e lição de casa}

Pode parecer estranho falar sobre espaço privado em primeiro lugar quando se trata de colaboração. Mas como o esforço coletivo se alimenta do trabalho de cada membro do grupo, é necessário que todos tenham um local para realizar determinadas atividades e se preparem para compartilhá-las com o grupo. Espaço privado é aquele que cada um constrói para si, à sua maneira, em seu posto de trabalho. De acordo com suas necessidades e preferências, o aluno instala ferramentas, cria rotinas de trabalho, organiza e gerencia os objetos que optou por colocar ali. Ele pode dividir seu espaço privado para estendê-lo em um servidor remoto onde pode arquivar documentos ou processar dados ou informações usando sistemas que não podem residir em sua estação de trabalho. Portanto,

Dedicado fundamentalmente à pesquisa pessoal, reflexão, apropriação e produção de informação, o aluno trabalha em espaço privado para organizar seus pensamentos e ideias, desenvolver suas representações, fazer um balanço de seus conhecimentos, preparar suas intervenções e trabalhar na produção de documentos. irá compartilhar com o grupo. A partir deste universo pessoal, você deve ser capaz de acessar todos os outros espaços e todos os recursos do ambiente. A passagem de um espaço a outro ou de um recurso a outro deve ser transparente. Durante uma sessão de trabalho, o aluno deve ser capaz de se deslocar facilmente para o espaço de comunicação para se juntar a outros alunos ou para o espaço

comum para buscar informações, importar uma ferramenta de software, trabalhar lá a partir do servidor,

\section{O espaço comum: um foco de fluxos de formação}

O espaço comum é um verdadeiro centro de recursos multiuso que todos podem acessar. Contém várias ferramentas: didáticas, materiais metodológicos, várias fontes de informação, softwares, etc., e portanto reúne o hardware e o software que fomentarão a aprendizagem e que servirão para construir ou enriquecer o espaço privado. Além disso, o espaço comum é o local onde os alunos vêm para depositar suas produções. Acessíveis a todos, essas produções serão compartilhadas com o grupo e poderão ser comentadas e utilizando ferramentas de software disponíveis no ambiente.

As ferramentas de software encontradas no espaço comum podem ser, por exemplo, softwares de planejamento, gestão, produção escrita e multimídia, comunicação, recuperação de informação, auxílio na estruturação de suas atividades, ideias e representação do 
conhecimento. As ferramentas educacionais, didáticas, metodológicas podem assumir a forma de guias de estudo, apresentações de estratégias de aprendizagem, instruções de trabalho, tutoriais, etc. As fontes de informação presentes no ambiente também podem ser muito numerosas: documentos textuais ou multimídia, expressamente preparados para a formação em curso, acervos de documentos já publicados, bases de dados, bibliografias, gráficos web que orientam os alunos em sua gestão contra a busca de informações sobre o web, etc.

\section{Centro de validação de conhecimento - Espaço do grupo}

A colaboração é feita de interação e diálogo. A comunicação domina lá; é o cerne disso. Daí a importância que deve ser dada ao espaço de comunicação em ambientes de aprendizagem. É o lugar onde os alunos se encontram, é o lugar onde eles conversam. É aqui que o grupo se forma, onde sua dinâmica se cristaliza. É o espaço que permite ao grupo existir e viver. Posteriormente analisaremos em detalhe as características desta comunicação e apresentaremos as ferramentas que servem para mediá-la e apoiá-la. Digamos por enquanto que, neste espaço, os alunos comunicam de forma síncrona ou assíncrona, em linguagem natural, escrita ou falada.

O espaço de comunicação inclui ferramentas síncronas e assíncronas. Os mais usados são e-mail, quadro de mensagens ou fórum, quadro de avisos, chat e quadros brancos. Desse conjunto de ferramentas de comunicação, o fórum eletrônico é, para nós, o mais importante. Ele ganha facilmente outras ferramentas para apoiar a aprendizagem colaborativa à distância. Por funcionar em modo assíncrono, o fórum reúne os alunos independentemente das restrições de tempo e espaço. Concentre as comunicações permitindo que todos sejam ouvidos e proporcionando ao grupo locais para viver, interagir, trabalhar e socializar.

Antes de mergulharmos na comunicação em fóruns eletrônicos, primeiro veremos a importância da comunicação para a colaboração e o aprendizado.

\section{Aprendizagem, comunicação e colaboração}

Colaborar e aprender são essencialmente atos de comunicação que surgem do diálogo e da conversa. Eles são marcados pela benevolência, abertura e generosidade. São verdadeiros gestos cujo caráter autêntico deve ser preservado, mesmo que sejam divulgados. Nas próximas páginas tentaremos lançar luz sobre o funcionamento dessa comunicação mediada de forma a atender às condições que lhe são favoráveis em um ambiente colaborativo. 


\section{Comunicação e colaboração}

Um estudo realizado entre grupos de pesquisadores permitiu descrever a colaboração intelectual e os comportamentos dos colaboradores e compreender a importância da conversa neste processo. Garavit, J. et al (2021e). observou que colaboradores intelectuais se reúnem para compartilhar suas ideias, comunicar sua visão das coisas, desenvolver hipóteses, discutir e pactuar o direcionamento a ser dado ao trabalho. Durante as discussões, eles tentam reconciliar os pontos de vista uns dos outros e identificar um padrão unificador. Eles concordam quanto ao objetivo da colaboração e ao processo de trabalho. No entanto, os alunos nem sempre concordam e não precisam concordar. Eles podem se opor ou até mesmo entrar em conflito por respeito mútuo. Alcançar um consenso em todas as questões não é uma regra rígida e rápida. Pelo contrário, A colaboração é um pouco mais saudável e produtiva quando permite a expressão de ideias e pontos de vista divergentes e até opostos. Nesse sentido, cada grupo desenvolve um limite de tolerância para desacordo, mas se ultrapassar, a colaboração acaba.

Para os funcionários, o trabalho em grupo se alterna com o trabalho individual. Após os encontros, cada um segue seu caminho para seguir trabalhando. Eles se reunirão novamente, formal ou informalmente, com a frequência e ritmo acordados, para relatar o andamento de seus trabalhos, suas descobertas e suas reflexões. As contribuições de cada um serão analisadas, comentadas, criticadas e avaliadas de acordo com os resultados desejados.

Garavit, J. et al (2021e). Ele explica que é através da conversa que os colaboradores se encontram e que é através da conversa que se constrói a colaboração. Ao falar, a intenção tácita dos colaboradores é aprender com os outros, ou seja, entender o que os outros estão expressando, mas também se entender em relação aos outros. A conversa tem função mediadora; apóia a negociação que visa aproximar os pensamentos e diminuir a distância entre o estado de conhecimento de cada um.

Por meio da conversa, os alunos se adaptam uns aos outros, conseguem explicitar seus conhecimentos, se apropriar dos outros, traçar novos pontos de vista, desenvolver uma orientação comum e chegar a um consenso sobre uma visão compartilhada do trabalho a ser

realizado. O desafio dos colaboradores é negociar o alinhamento das perspectivas dos demais integrantes que gerem um esquema coletivo que oriente o trabalho. Nessa abordagem, a conversa é o lugar central de troca e negociação, o lugar de convergência do processo colaborativo. 


\section{Diálogo como padrão de aprendizagem}

Os funcionários aprendem uns com os outros. $\mathrm{O}$ mesmo pode acontecer com os alunos autônomos e responsáveis. É o que propõe Laurillard (1995) ao desenvolver um modelo de aprendizagem conversacional para estudantes universitários. Este modelo, especialmente adequado para a aprendizagem de adultos, reconhece que a aquisição de conhecimentos é um processo sociocognitivo. Ele aborda a aprendizagem complexa e é projetado para apoiar o surgimento de conhecimento abstrato. Com base em Linard (1995), Laurillard entende o conhecimento abstrato como aquele que vai além do conhecimento pragmático e de primeiro nível, derivado do senso comum, percepções, representações e ação. Seu modelo conversacional orienta e estrutura o intercâmbio entre instrutores e alunos. É estruturado em torno de quatro funções principais,

- Para o formador, a função discursiva ajuda a identificar a lacuna entre o modelo de conhecimento dos alunos e o modelo de conhecimento do especialista; requer a declaração de ideias, visões e perspectivas de cada aluno. O formador e os formandos esforçam-se por identificar um esquema ou modelo coletivo de conhecimento.

- A função adaptativa visa que o formador adapte as suas intervenções ao estado de conhecimento dos alunos.

- A função de interação fornece aos alunos um feedback sobre os resultados das experiências concretas e práticas que realizaram para aplicar e manipular objetos de conhecimento. Envolve a partilha do trabalho realizado individualmente e dos resultados obtidos.

- A função reflexiva é aplicada a todo o processo objetivo-ação-feedback com o intuito de gerar novos conhecimentos a partir do que os alunos descobriram em vários momentos de aprendizagem. Esta função visa produzir conhecimentos de segundo nível, abstratos e descontextualizados, como princípios, conceitos, métodos, etc.

O modelo de conversação é adequado para o processo colaborativo. Isso nos lembra que a reflexão e o feedback sobre o processo do aluno são essenciais para a aprendizagem; que permitem aos alunos dar um passo para trás, objetivar os novos conhecimentos e avaliar o processo de aquisição desses conhecimentos.

\section{Comunicação síncrona ou assíncrona}

Essa revisão da conversa como prática de comunicação para colaborar e aprender nos leva a refletir sobre as ferramentas mais adequadas para mediar esse tipo de comunicação. Portanto, vamos revisar as prerrogativas e os prejuízos das ferramentas síncronas e assíncronas. 
As ferramentas de comunicação síncrona permitem que pessoas distantes se comuniquem em tempo real. Livres de restrições espaciais, eles devem cumprir um cronograma acordado para cumprir. Esses sistemas são projetados para comunicação imediata. Eles são muito populares entre os grupos para se encontrarem e se socializarem. São eficazes na tomada de decisões rápidas, coordenação de atividades e aconselhamento e assistência técnica (de la Teja, Lundgren \& Paquin, 1997). Esses encontros virtuais são efêmeros por natureza. Eles se prestam bem a trocas que devem levar a um resultado imediato. Embora a maioria das ferramentas síncronas permita que você acompanhe o encontro e revise-o após o término do evento, mesmo que não tenham sido projetadas para esse propósito.

Além disso, a comunicação assíncrona libera restrições e tempo e espaço. Conforme sua conveniência, dia ou noite, os participantes se juntam ao grupo para trocar, discutir, conversar. A duração dessas reuniões virtuais pode durar semanas, meses ou até anos. Os participantes têm tempo para permitir que suas ideias amadureçam. Nesse sentido, nosso trabalho com grupos de educação a distância tem nos permitido observar que as trocas são mais efetivas entre os alunos.

As trocas assíncronas costumam ser muito mais ponderadas, melhor estruturadas e mais profundas do que as trocas síncronas. Porque antes de fazer suas intervenções, os alunos podem reler, analisar e entender melhor as contribuições dos outros. Como as mensagens são armazenadas, elas podem ser visualizadas a qualquer momento. O traço da discussão, permanentemente acessível, ajuda os alunos a compreenderem o desenvolvimento do seu trabalho e o sentido que este lhe confere. Além disso, para o grupo, a análise desse traço vem se revelando uma excelente forma de revisar sua funcionando e traçando caminhos para uma melhor colaboração.

Alguns pensarão que a comunicação assíncrona logo será suplantada pela comunicação síncrona considerada mais natural e fácil de usar e cuja popularidade está crescendo para trocas em grupo pela telemática. Mas, em nossa opinião, o modo assíncrono sempre terá destaque nas abordagens de ensino à distância. As vantagens da assincronicidade são inegáveis para a colaboração e o ensino à distância devido à flexibilidade de trocas que proporciona e à profundidade de conteúdo que possibilita. Como esperamos mostrar aqui, dá origem, no âmbito dos fóruns eletrónicos, à implementação de processos colaborativos inovadores que o modo síncrono nunca nos permitiu alcançar.

Porém, Para que a comunicação assíncrona se torne um veículo de aprendizagem poderoso e cada vez mais bem-sucedido, é necessário ser capaz de oferecer aos alunos ferramentas mais eficazes do que as que existem atualmente para mediar e apoiar a colaboração de forma mais eficiente. Estamos pensando aqui em videoconferência e nos diversos programas de "bate-papo" agora disponíveis na web que oferecem uma variedade de funções, como lista de presença, várias janelas, compartilhamento de documentos, quadro 
branco, chamadas. Sites de URL, e-mail, etc. agora disponível na web, oferecendo uma variedade de funções, como lista de presença, várias janelas, compartilhamento de documentos, quadro branco, chamadas. Sites de URL, e-mail, etc. agora disponível na web, oferecendo uma variedade de funções, como lista de presença, várias janelas, compartilhamento de documentos, quadro branco, chamadas. Sites de URL, e-mail, etc.

\section{Interação, assíncrona (escrita)}

Nos ambientes virtuais que nos interessam, as interações humanas desempenham um papel preponderante. Não é a imagem que predomina, mas a palavra escrita que serve de veículo e ferramenta privilegiada de apoio às atividades de construção do conhecimento. Isso explica o uso inevitável de fóruns eletrônicos em ambientes de aprendizagem colaborativa. Nesta parte, queremos mostrar que, se essa tecnologia é amplamente utilizada para colaboração, não é por padrão ou porque está ao alcance de todos, mas porque esconde um potencial educacional apreciável.

\section{Tecnologias de comunicação assíncrona}

Qual é a diferença entre o fórum eletrônico (geralmente chamado de fórum de discussão), o e-mail, o quadro de avisos e o coletivo? Não são ferramentas que se parecem e têm os mesmos propósitos? O e-mail não permite que você poste em grupos como o e-fórum e o quadro de avisos? O que distingue essas ferramentas? Como costumam estar integrados num mesmo sistema e podemos navegar facilmente de um para o outro de forma transparente, não é fácil perceber que induzem uma dinâmica de comunicação muito diferente. Uma coisa é certa, todos estão a serviço dos grupos e da comunicação humana. Mas cada uma dessas ferramentas desempenha uma função diferente. Iremos descrevê-los separadamente para entender melhor suas diferentes funções.

Groupware são ferramentas criadas para facilitar a manipulação de informações em bancos de dados usando uma ou mais interfaces programáveis. Fraase (1991) os define como: "Groupware é sobre pessoas que gerenciam seus recursos coletivos de informação em conjunto. São ferramentas de produtividade de grupo desenvolvidas para empresas. Eles facilitam a organização e o acesso a informações para grupos que precisam, coletivamente, concluir uma tarefa ou projeto. Esses sistemas permitem a manipulação e processamento de informações relacionadas à tarefa, seu gerenciamento e seu desempenho. Ao contrário dos fóruns eletrônicos, o groupware não se destina principalmente a apoiar o processo dinâmico de comunicação em grupo remotamente,

Os quadros de avisos, ou ferramentas de comunicação para grupos de interesse, são construídos de acordo com o princípio dos quadros de avisos (Gunawardena, 1991a e 1991b). 
Usados na maioria das vezes pelo conjunto cooperativo de alunos para realizações frequentes, eles permitem que as informações sejam registradas em um local acessível a esses indivíduos. A principal função dos quadros de avisos é facilitar o fluxo de informações, independentemente da tarefa ou projeto comum em questão. Os usuários desses sistemas não são grupos de colaboradores. Eles formam grupos de pessoas que buscam iniciativas pessoais que não estão vinculadas a uma abordagem coletiva.

Os fóruns eletrônicos foram projetados para facilitar as interações humanas e estruturar a dinâmica de grupo. A sua arquitetura, funcionalidades e interfaces convidam os utilizadores a aderir ao grupo, a interagir com ele, a colaborar e a participar ativamente nas suas atividades. Observadores silenciosos (stalkers), que freqüentam quadros de avisos, não têm lugar em um fórum. A interface incentiva os usuários a participarem. Quase todos os gestos, quase todos os cliques exigem uma ação ou decisão de engajamento. Após ler cada mensagem, o usuário é convidado a reagir. Você quer escrever uma mensagem? Você quer responder? Você gostaria de fazer um comentário? Quer encaminhar a mensagem para outro fórum? A dinâmica das trocas é constantemente estimulada.

No início de cada mensagem, os participantes indicam o assunto e indicam o vínculo entre a mensagem que estão redigindo e as mensagens anteriores. É um estímulo para relevância e consistência. A qualquer momento, é possível visualizar as mensagens anteriores para reconstruir o quadro da discussão; é um estímulo para desenvolver um argumento. Ao longo das mensagens, são estabelecidas ligações entre ideias e também entre participantes. Quando as discussões são conduzidas por um bom moderador e o objetivo é significativo.

Quem está acostumado a fóruns eletrônicos sempre se surpreende ao observar o ímpeto das cooperações que se estabelecem entre os participantes, a riqueza de informações decorrentes da conversa e da troca de ideias (Harasim, 1990; Hiltz, 1987). Os designers de sistemas de fóruns eletrônicos reconhecem a necessidade da intervenção de um moderador para garantir o funcionamento efetivo do grupo. É por isso que você tem os direitos exclusivos para organizar e gerenciar as trocas do grupo.

Os sistemas de fóruns eletrônicos permitem que um determinado grupo configure seu próprio espaço de comunicação, fazendo de cada fórum um lugar com uma vocação única e específica. Alguns fóruns podem ser reservados para a vida social do grupo, outros para o planejamento do trabalho e outros para a realização de tarefas e coordenação de esforços. Sempre é possível para um grupo de trabalho revisar o design de seus fóruns. Você pode dividir um tópico que é repentinamente considerado muito amplo em vários subtópicos e criar um novo e-fórum para cada um; os fóruns podem ser reorganizados para abordar um novo tópico ou para resolver um problema que o grupo considera importante 
A navegação entre os fóruns reservados para um grupo geralmente é perfeita. Em vários sistemas, é possível alternar automaticamente de um fórum para outro, o que incentiva os membros a tomarem nota de todas as discussões sobre todos os tópicos que dizem respeito ao grupo.

Software coletivo, quadros de avisos e fóruns são ferramentas de colaboração, cada um dos quais dá uma contribuição específica para o trabalho em grupo. Nosso interesse no fórum decorre do fato de que ele pode responder, mais do que outras ferramentas, a um amplo espectro de necessidades entre grupos colaboradores.

\section{Tabela 2.2}

\section{Os Fóruns Eletrônicos}

\begin{tabular}{|c|c|}
\hline $\begin{array}{c}\text { Fórum } \\
\text { Eletrônico }\end{array}$ & Para o Aprendiz \\
\hline O que é ?. & $\begin{array}{l}\text { É um lugar virtual onde se constrói o discurso de um grupo, onde o aluno se apropria de novos } \\
\text { conhecimentos conversando com outras pessoas. } \\
\text { É uma ágora de colaboração e socialização. }\end{array}$ \\
\hline $\begin{array}{c}\text { O que } \\
\text { permite? }\end{array}$ & $\begin{array}{l}\text { Você pode apresentar ideias, desenvolver seus pensamentos, construir novos conhecimentos, } \\
\text { validá-los e confirmá-los com o apoio do grupo. } \\
\text { Facilita a aprendizagem de conhecimentos complexos pertencentes a áreas mal ou mal } \\
\text { estruturadas. } \\
\text { Promove uma atitude reflexiva em relação à aprendizagem. } \\
\text { Permite a um grupo ter uma experiência de aprendizagem motivadora e desenvolver um } \\
\text { envolvimento sócio-cognitivo que dá à aprendizagem ainda mais significado. }\end{array}$ \\
\hline $\begin{array}{c}\text { Quem } \\
\text { participa? }\end{array}$ & $\begin{array}{l}\text { Agentes humanos que criam uma rede social: o tutor ou formador e outros alunos que } \\
\text { trabalham em pequenos grupos (colaboração espontânea, informal) ou em grande grupo } \\
\text { (colaboração supervisionada, formal). } \\
\text { Agentes de máquina que compõem o ambiente tecnológico: ferramentas de colaboração, } \\
\text { coordenação e suporte a processos cognitivos e sociais. }\end{array}$ \\
\hline $\begin{array}{c}\text { Como } \\
\text { participamos? }\end{array}$ & $\begin{array}{l}\text { Os agentes humanos transmitem mensagens ao grupo; a interação é a semântica dessas } \\
\text { mensagens. } \\
\text { Os agentes de máquina, enxertados no fórum, fornecem suporte de aprendizado de máquina, } \\
\text { por exemplo, fornecendo várias representações do que é dito nas postagens; este suporte é } \\
\text { imediato, rápido e interativo. }\end{array}$ \\
\hline $\begin{array}{l}\text { Quando é } \\
\text { melhor usá- } \\
\text { lo? }\end{array}$ & $\begin{array}{l}\text { Quando a aprendizagem envolve habilidades de análise, síntese e avaliação, o fórum é uma } \\
\text { opção educacional adequada. Portanto, é concebido como um ambiente de resolução de } \\
\text { dificuldades e confiança nas decisões tomadas. } \\
\text { Ele atesta a intencionalidade da situação de treinamento. } \\
\text { Em um ambiente de aprendizagem formal, quando os alunos sentem que precisam que outros } \\
\text { aprendam, quando um grupo de } 15 \text { a } 30 \text { alunos deseja aprender junto com o apoio de um } \\
\text { treinador e quando estão dispostos a ajudar. Ouça para alcançar um objetivo comum. } \\
\text { Em um ambiente informal, quando um número suficiente de pessoas deseja formar um grupo } \\
\text { e trabalhar juntas para aprender. }\end{array}$ \\
\hline
\end{tabular}

Garavit, J. 2021 


\section{Condição humana de comunicação}

O fórum reúne grupos em um espaço virtual e os oferece para se comunicarem em modo conversacional. Essas conversas evoluem como as dos alunos que, no decorrer da conversa, desenvolvem novas ideias. Em um fórum, todos têm o direito de falar e todos são convidados a expressar suas idéias e reagir às dos outros. A alternância de mensagens não está sujeita ao turno de fala da conversa verbal. As regras de etiqueta e o código de conduta para conversas orais não se aplicam, os participantes do fórum são libertados da ordem sequencial do discurso e da regra de cortesia que exige que os interlocutores falem um de cada vez e respondam ao que acabou de ser dito (Davie e Wells, 1991).

A qualquer momento é possível expressar diferentes pontos de vista, ideias divergentes ou mesmo polêmicas. De uma mensagem para outra, o conteúdo não precisa estar diretamente relacionado à anterior. Você pode responder a uma mensagem que aparece muito mais alto na tela. A desordem que pode ser observada na transcrição cronológica de um fórum eletrônico só é aparente porque as funcionalidades permitem traçar os links entre as mensagens. Assim, certos comandos permitem agrupar mensagens relacionadas a uma mesma ideia ou a um mesmo objeto e reconstituir o curso do raciocínio ou da argumentação.

A assincronicidade do fórum eletrônico oferece muitas vantagens em relação à transitoriedade da conversa face a face. Numa troca síncrona, todos dão informações, afirmam o seu ponto de vista e reagem de forma espontânea ao que acaba de ser dito, às vezes esquecendo o que foi dito na ata anterior. Uma boa ideia pode ser perdida, mal interpretada ou distorcida sem poder ser retomada ou esclarecida, dificultando a colaboração (Burge, 1994; Davie e Wells, 1991). Nem a memória dos colaboradores nem as anotações podem dar um relato autêntico e objetivo do andamento das conversas. Em um fórum, as ideias não desaparecem, as mensagens são armazenadas na memória e se tornam objetos tangíveis que podem ser manipulados, colocados em um banco de dados, anotados, comentados, criticados, reestruturados, etc.

O fórum se presta muito bem à livre expressão de pontos de vista opostos e à elaboração de vários argumentos em paralelo. Os recursos de marcação e classificação de postagem permitem que você rastreie o fio das ideias. Assim, dentro dos grupos pode haver troca real, aprendizagem mútua e o surgimento de colaboração genuína (Pugh, 1993; Solomon, 1992). Em um contexto de aprendizagem, o modo de conversação específico do fórum pode ser aproveitado para apoiar o modelo de aprendizagem proposto por Laurillard que mencionamos anteriormente e resumido aqui, adotando o ponto de vista do aluno. 
- A função discursiva: Permite trazer à tona o estado de conhecimento, é exercido graças à possibilidade que os alunos têm de expressar vários pontos de vista e de desenvolver paralelamente uma série de argumentos ou sobre um determinado tema.

- A função adaptativa: Garantido pelo armazenamento de mensagens e pela possibilidade de as consultar a qualquer momento. $\mathrm{O}$ formador pode, através da leitura das mensagens, identificar um esquema ou modelo coletivo de conhecimento a partir do qual irá orientar as suas intervenções e o resto da aprendizagem.

- O fórum está a serviço da interação e da função de feedback. Depois de trabalharem individualmente, depois de terem manipulado, aplicado e experimentado objetos de conhecimento, os alunos reúnem-se nos fóruns para compartilhar os resultados obtidos e receber comentários e feedbacks do formador e do grupo.

- A função reflexiva:Seu objetivo é retornar ao processo colaborativo, a extração de conhecimentos de segundo nível e objetivação. É facilitado com a memorização de mensagens que oferece a possibilidade de rever a transcrição das trocas, analisando o comportamento do grupo e avaliando sua produção e sua produtividade.

\section{Objetivos epistemológicos}

Podemos dizer do fórum eletrônico, textual e assíncrono, que é uma ferramenta flexível que facilita a colaboração remota e promove o aprendizado. $\mathrm{O}$ seu funcionamento, baseado no modelo conversacional e de comunicação assíncrona, e as suas características tecnológicas, que permitem a criação de locais com vocações específicas, a recuperação de vestígios de trocas e a ordenação de mensagens, apoiam os processos sociais e cognitivos de grupos de pessoas. ou alunos. No entanto, temos que admitir que os sistemas de fórum de que dispomos atualmente impõem limites à implementação desses processos.

\section{Demarcação de aspectos sociais}

A presença social é apenas fracamente expressa em um fórum eletrônico. A ausência de pistas verbais (tom, atitude, gesto, etc.) pode gerar incerteza entre os participantes. Algumas pessoas não sabem se são aceitas pelo grupo ou não percebem seu lugar dentro do grupo. Então, é difícil para eles colaborar e desenvolver um senso de pertencimento (Burge, 1994). Além disso, a ausência de pressão social nem sempre tem um efeito positivo na colaboração. Aumenta o sentimento de liberdade pessoal e pode fomentar o individualismo que, se desenvolvido, ameaça a coesão e a produtividade do grupo. Os moderadores do fórum geralmente estão cientes dessas limitações. Eles sabem como usar estratégias para neutralizar os efeitos negativos de uma presença social fraca. Por outro lado. 


\section{Conclusões das causas nos avanços do pensamento}

Em um fórum, as funções de marcação e classificação permitem agrupar mensagens relacionadas ao mesmo tema e acompanhar a evolução da conversa e o desenvolvimento de ideias. Essa representação da discussão, linear à vontade, não reflete o processo recursivo de desenvolvimento do pensamento. Quando o pensamento é construído, as idéias não vêm à mente em uma ordem, estrutura ou formulação final. Seja para elaborar um raciocínio ou desenvolver um conceito, para construir um argumento ou para desenvolver o fio condutor de um pensamento, as ideias são ordenadas e especificadas recursivamente. Muito feedback é necessário para revisar, esclarecer, explicar, elaborar ou estruturar o que foi imaginado, dito ou escrito. Esse processo não é linear e nem sempre ocorre de acordo com a lógica óbvia.

O texto de um fórum é plano e linear; é unidimensional e oferece somente leitura sequencial. A sequência de mensagens que uma pessoa exibe na tela ou imprime parece confusa, especialmente quando se está interessado nos processos de pensamento e deseja observar sua evolução. A simples transcrição de um fórum não traduz claramente a estrutura desenvolvida pelo grupo. A apresentação do conteúdo das mensagens não reflete o resultado da atividade cognitiva do grupo nem reflete o exercício de pensamento em que os participantes estiveram envolvidos.

Pedimos que os sistemas de fórum ofereçam mais do que foram projetados. Queremos que eles gerem representações dos processos cognitivos do grupo (espiral, arborescente, molecular, circular, lateral, raciocínio multidimensional, etc.; Processo de revisão, comparação, reestruturação, etc.) enquanto se trata mais do armazenamento de intervenções do que objetivo. Para melhor servir a comunicação grupal e a aprendizagem colaborativa, esses sistemas se beneficiariam da integração de funcionalidades que aumentassem sua capacidade de representação, mostrando, por meio de formas mais dinâmicas, mais visuais ou simbólicas, os caminhos que levam às construções mentais. Os desenvolvedores podem fazer isso primeiro inserindo ferramentas de brainstorming, mapas conceituais, hipertexto, etc.

Sem dúvida, o texto teria que ser manipulado no início para garantir seu tratamento por essas ferramentas, mas o exercício valeria a pena na medida em que serviria para estabelecer o mérito de nossas solicitações. É nesta perspectiva que atualmente estão trabalhando no desenvolvimento de ferramentas de análise de texto que possam ser adicionadas aos fóruns. Eles permitem que estruturas que de outra forma seriam invisíveis surjam e forneçam uma imagem dinâmica. Dessa forma, formadores e alunos puderam observar as representações que eles produzem, o que deve favorecer um certo controle sobre suas habilidades cognitivas. Apesar de suas limitações, o fórum não deve ser negligenciado como ferramenta de apoio ao treinamento colaborativo. Apesar de tudo. 


\section{Demarcação de julgamento reflexivo}

O armazenamento do trace é apontado como um dos pontos fortes do fórum eletrônico. Ao consultar o histórico das trocas, o aluno pode a qualquer momento rever o conteúdo das mensagens e aproveitar para refletir sobre a dinâmica em que o grupo participa. Ao analisar as mensagens, você também pode compreender melhor o significado de uma discussão e direcionar melhor suas intervenções. No entanto, podemos ver que retroceder não é uma prática comum entre os participantes. Os sistemas de fórum são parcialmente responsáveis por isso, já que raramente incentivam os participantes a revisar as postagens anteriores antes de intervir. Os comandos que aparecem no final das mensagens convidam você a reagir imediatamente, online, sem pensar. O que mais, Como não é obrigatório declarar o link entre uma nova postagem e as anteriores, divagações e pontos confusos são comuns em fóruns. É quando o moderador deve demonstrar muita habilidade para manter o grupo no caminho certo.

Embora os sistemas de fórum atuais ofereçam alguns recursos para explorar o histórico da conversa, eles não são óbvios e geralmente são pouco usados pelos alunos. Você deve deixar o moderador sugerir que os participantes o façam. Isso também pode apoiar o processo de reflexão, encorajando os alunos a não responder espontaneamente online, mas a reservar um tempo para refletir antes de escrever suas mensagens offline. Além disso, ao pedir que indiquem a que mensagem estão respondendo e o link que será estabelecido, o moderador incentiva o processo de reflexão. A reflexão e exploração do conteúdo das mensagens é uma disciplina intelectual importante que deve ser adquirida.

\section{A organização de trocas}

Em um ambiente de treinamento colaborativo, cada fórum tem uma vocação específica. O objetivo, o conteúdo de aprendizagem, a tarefa e o fluxo de trabalho são claramente identificados. Podem ser atividades cognitivas simples, como a troca de informações sobre um determinado assunto, ou atividades mais complexas, como fazer um estudo de caso, tomar uma decisão, analisar uma teoria, etc., ou ainda atividades de natureza social ou organizacional. É uma pena que, para realizar uma variedade de tarefas, os sistemas ofereçam apenas uma e a mesma estrutura. Todos os fóruns, seja qual for a natureza da atividade a ser desenvolvida (Harasim, 1990; Hiltz, 1987) são organizados e conduzidos da mesma forma. Devemos nos adaptar ao mesmo ambiente e às mesmas funcionalidades para realizar tarefas cognitivas, realizar atividades de socialização e assegurar intervenções de acompanhamento e coordenação do trabalho.

Como se, na escola, as ações desenvolvidas no período escolar (aulas, recreio, laboratórios, almoços, etc.) fossem desenvolvidas na mesma sala com os mesmos recursos. 
Para evitar este problema, o facilitador deve planear com rigor as diferentes etapas e, através de instruções muito precisas, informar os alunos das regras de participação que se aplicam a cada fórum; é um fardo que se soma à sua já pesada tarefa de facilitador psicossocial e suporte cognitivo e organizacional. ) foi desenvolvido na mesma sala usando os mesmos recursos. Para evitar este problema, o facilitador deve planear com rigor as diferentes etapas e, através de instruções muito precisas, informar os alunos das regras de participação que se aplicam a cada fórum; é um fardo que se soma à sua já pesada tarefa de facilitador psicossocial e suporte cognitivo e organizacional. ) foi desenvolvido na mesma sala usando os mesmos recursos. Para evitar este problema, o facilitador deve planear com rigor as diferentes etapas e, através de instruções muito precisas, informar os alunos das regras de participação que se aplicam a cada fórum; é um fardo que se soma à sua já pesada tarefa de facilitador psicossocial e suporte cognitivo e organizacional.

\section{Conclusões de conversas e linguagem verbal}

O fórum, como já foi dito, usa a linguagem verbal e adota a conversa como forma de representação. Embora reconheçamos o poder dessa forma de discurso, devemos admitir que raramente é inequívoca e que a ambigüidade inerente às conversas muitas vezes cria confusão, o que afeta a produtividade e o bom funcionamento de grupos colaborativos. Além disso, sabemos que a colaboração vive e se mantém graças à diversidade de contribuições e à multiplicidade de pontos de vista. Os sistemas de fórum baseados em texto não devem ser limitados ao uso exclusivo da linguagem verbal e do modo de conversação. Seria vantajoso procurar aquelas que permitissem a integração ou a criação de vínculos para formas de múltiplas representações.

Os alunos devem ser capazes de usar outras ferramentas que permitem o uso de outras linguagens (matemática, computação, visual, etc.) e criar outras representações (diagramas, equações, imagens, modelos, etc.) que podem ser consultadas, compartilhadas e manipulado pelo grupo no espaço comum. Essas ferramentas de colaboração periféricas ao fórum e usadas para expressar e comunicar o que não pode ser facilmente explicado em palavras garantiriam que todos tivessem os meios adaptados à expressão de seu modo de pensar. Se insistimos na importância de poder reproduzir múltiplas representações, é porque a verdadeira colaboração exige que cada um se expresse, que todos possam compreender as contribuições dos outros e que coletivamente apreendam o sentido da tarefa. .se realizada,

\section{Iniciativa para uma colaboração celebrada}

Apesar da falta de um espaço físico comum para compartilhar, os alunos reunidos em um fórum descobrem uma capacidade insuspeitada de ação e socialização. Você pode criar e desenvolver uma vida em grupo no espaço virtual. Relacionamentos de amizade são 
formados, conflitos surgem, sentimentos de desânimo e entusiasmo ocorrem; Humor, protesto, retraimento se manifestam. Para otimizar o sucesso da colaboração, cinco fatores humanos devem ser considerados: participação, motivação, animação, coesão e produtividade do grupo (Garavit, J. 2017).

É escrevendo e transmitindo mensagens que você participa de um fórum eletrônico; a presença de leitores silenciosos é mal tolerada. Todos devem contribuir. A equação é simples: sem posts, sem participação, sem fórum. A falta ou ausência de participação pode ter várias causas que o designer do ambiente não pode controlar, e é difícil para o participante acessar uma estação de trabalho ou o ambiente de TI no momento desejado:

- Habilidades de baixa tecnologia.

- Falta de tempo para se comunicar.

- Má capacidade de leitura ou escrita.

- Falta de atração pela linguagem verbal.

- Falta de motivação.

Por outro lado, o designer pode incentivar a participação planejando cuidadosamente o ambiente e fazendo com que os alunos entendam claramente suas intenções pedagógicas e as regras de colaboração.

\section{Valorização real da colaboração}

Em sua abordagem ao design educacional, o designer escolhe os recursos e ferramentas do ambiente colaborativo. Defina seus usos e funções. Desenvolva um raciocínio para justificar a realização de um ou mais fóruns. Sua lógica de design o levará a determinar o lugar dos fóruns no ambiente e a função que eles terão de desempenhar na aprendizagem. Se, para o designer, o processo de aprendizagem é baseado em trocas e interações escritas, os fóruns vão ocupar um lugar central no ambiente. Portanto, para que um ambiente de treinamento seja colaborativo, não basta que o designer o declare como tal e abra um fórum ou dois convidando os alunos a participarem.

Se queremos que se desenvolva uma verdadeira colaboração no ambiente, devemos assegurar que os fóruns não se tornem meras salas de chat, utilizadas ocasionalmente para atender às necessidades individuais. Mesmo antes do início de seu treinamento, os futuros alunos devem ser informados sobre o propósito do aprendizado e sua finalidade. Devem ser explicados os princípios de colaboração, os requisitos do trabalho em grupo, o ritmo e a frequência da participação. Essas informações serão comunicadas de forma mais eficaz se o próprio designer tiver uma visão e compreensão profundas do significado da participação e 
do uso reservado do fórum em um processo colaborativo. Os alunos que decidirem participar deste processo o farão com pleno conhecimento dos fatos. Desta forma,

Portanto, é importante que o aluno conceba de forma fundamentada o elo entre formação colaborativa, comunicação e participação em fóruns; Recorde-se que a colaboração se baseia na busca de um objetivo comum, mas que também deve atender às suas intenções pessoais. Você também deve entender que, na abordagem de formação que você escolheu, também será uma questão de aprender a colaborar e que aprender a colaborar faz parte dos valores e objetivos educacionais que o designer subscreve. Em última análise, o aluno deve desenvolver uma percepção positiva da colaboração, vendo-a como um valor agregado.

Essa percepção será reforçada pelas práticas de facilitação, pelo feedback dado ao aluno e pela avaliação do treinamento. Uma vez que os alunos tenham decidido participar do treinamento e tenham concordado em aprender a colaborar, o grupo pode discutir e negociar o propósito e as modalidades de participação: o objetivo comum, o trabalho de orientação e a organização da tarefa de aprendizagem, papéis, frequência de comunicações, horas, etc. Deve ser lembrado que, sem consenso sobre o propósito e as modalidades de participação, é impossível construir comunidade e garantir que os membros aprendam juntos.

\section{A motivação}

A colaboração é pragmática; permite satisfazer uma necessidade. Aos olhos dos colaboradores, não há nada de teórico sobre isso; adquire um caráter utilitário, orientado para a realização de uma tarefa concreta. É uma forma eficaz de atingir um objetivo e de se beneficiar da ação coletiva. A colaboração é um fenômeno fundamentado, apoiado por elementos de motivação extrínseca e intrínseca encontrados em vários graus nos alunos.

\section{Motivação extrínseca}

Então é preciso: juntar-se aos outros. Independentemente de quem são os outros contribuidores, você está sinceramente comprometido com o grupo. O aluno se adapta ao ambiente e se adapta ao grupo na medida em que se sente competente em relação a ele e está convicto de que o grupo pode auxiliá-lo na realização da tarefa de aprendizagem. Quando a motivação extrínseca se instala, você não percebe a colaboração como uma armadilha. Eles entendem que seu compromisso não é permanente, que a colaboração é limitada no tempo e que uma vez concluída a tarefa, ela chegará ao fim. As recomendações interpessoais que se desenvolvem dentro do grupo são importantes para o educador, mas a colaboração não está subordinada a elas. 
A motivação extrínseca preocupa-se principalmente em gerenciar os pontos fortes individuais, em vez de identificar fraquezas, críticas e queixas. Na medida em que cada um contribui de acordo com suas habilidades, o aluno aceita seus colaboradores, embora, em outras circunstâncias, não queira estar com eles. Baseia-se na originalidade e especificidade das contribuições de cada um, na interdependência positiva e na produtividade do grupo para ajudá-los a cumprir a tarefa de aprendizagem. Tudo isso explica que quando as colaborações terminam, os colaboradores vivenciam um sentimento de tristeza e liberação. Eles estão tristes porque as pessoas com quem trabalharam de forma tão eficaz e produtiva não estarão fazendo mais trabalho. Além disso, eles se sentem liberados porque, uma vez que o trabalho

é concluído, os alunos são livres e não se sentem obrigados ao grupo. A ideia de uma colaboração frutífera pode, eventualmente, encorajar esses colaboradores a experimentar a colaboração novamente.

\section{Motivação intrínseca}

A motivação intrínseca encontra sua origem no prazer de interagir, no desejo de participar da vida grupal e de se envolver, na sede de descobrir através do grupo o sentido que deve ser dado à aprendizagem. Emana da necessidade de auto-realização por meio da participação em uma comunidade de aprendizagem. $\mathrm{O}$ aluno então percebe a abordagem coletiva como uma oportunidade de crescer e transformar não só integrando novos conhecimentos, mas também desenvolvendo capacidades colaborativas e aprendendo a usar a tecnologia para fazer isso acontecer. A motivação intrínseca pode ser mantida e reforçada pensando sobre os valores da colaboração e os benefícios de dominar os processos.

\section{Atividades motivacionais de grupo}

A animação dos fóruns eletrônicos está a cargo de um moderador. Desempenha um papel fundamental de referência no funcionamento do grupo. Escolha um estilo de facilitação adaptado ao perfil do grupo para criar um clima propício à colaboração, incentivar a participação de todos, estimular interações e garantir a regulamentação do fluxo de trabalho. Sua missão é facilitar o alcance da meta da forma mais eficiente possível. Deve ser capaz de gerar uma dependência autêntica entre os membros para que todos sintam que suas experiências e contribuições são valorizadas e enriquecedoras para o grupo. Os fóruns de facilitação requerem que o facilitador domine as habilidades comuns das instalações. $\mathrm{O}$ facilitador do fórum lidera uma série de intervenções e desempenha papéis facilitadores que já foram bem descritos. Mason (1993) e Berge (1995) falam de intervenções de apoio cognitivo e pedagógico, animação social, apoio técnico e gestão da discussão. Para Dimock (1987) e St-Arnaud (1989), os papéis desempenhados pelo facilitador podem ser os de diretor, treinador, facilitador de conteúdo, procedimento e clima e distribuidor de tarefas. 
Feenberg (2007), por sua vez, propõe três tipos de intervenções específicas para a facilitação de fóruns: contextualização, controle e metafunções. As intervenções de contextualização visam introduzir o tema da discussão para estruturá-lo, estabelecer as etapas e o plano de trabalho e pactuar o funcionamento do grupo (procedimento a seguir, código de ética, etc.). Eles acontecem principalmente no momento do início das trocas.

As intervenções de controle devem ser tão flexíveis quanto possível. O moderador garante a coesão e produtividade do grupo, a manutenção da participação, o andamento da tarefa, etc. As intervenções que Feenberg qualifica como metafunções levam o moderador a ter uma visão global da atividade do grupo para ajudá-lo a identificar o significado de seu trabalho. $\mathrm{Na}$ abertura de um fórum, propõem a orientação a ser dada ao trabalho e, ao final, oferecem ao grupo uma visão geral do que foi alcançado. Após a conclusão de cada etapa, assumem a forma de resumos ou conclusões a fim de estabelecer vínculos entre si.

No âmbito da formação à distância, é o formador quem desempenha o papel de moderador e quem se encarrega do grupo. Sua função é estimular a participação dos alunos, fornecendo suporte motivacional e supervisão pedagógica. Como moderador, também exerce as funções de anfitrião social, facilitador de trocas e gestor do trabalho do grupo. Nos escritos, é explicado que as funções de animação são multidimensionais. Eles estão relacionados a vários níveis de discurso: pedagógico, cognitivo, metacognitivo, organizacional e social. Observa-se também que eles têm efeitos na coesão e na produtividade do grupo.

Para determinadas atividades realizadas no âmbito dos fóruns eletrónicos, o formador irá partilhar com os alunos as suas responsabilidades de moderador, visto que deve favorecer e incentivar o desenvolvimento da sua autonomia. Os alunos se revezarão atribuindo algumas ou todas as funções de facilitação. A prática da autoanimação é uma forma de desenvolver a responsabilidade pela aprendizagem uma vez que deve ser ativo e trabalhar, como formador, para esclarecer os conteúdos, estabelecer ligações e associações entre ideias., Formular hipóteses, resolver problemas e avaliar os resultados ( consulte a Tabela 2.3) 


\section{Tabela 2.3}

A função de moderador entre os alunos

\begin{tabular}{|c|c|c|}
\hline \multirow{2}{*}{$\begin{array}{l}\text { Funções de } \\
\text { animação de um } \\
\text { grupo virtual }\end{array}$} & \multicolumn{2}{|c|}{ Compartilhando a função de moderador } \\
\hline & $\begin{array}{l}\text { Responsabilidades } \\
\text { do treinador }\end{array}$ & Responsabilidades do aluno \\
\hline Contextualização & $\begin{array}{l}\text { Dar as boas vindas. } \\
\text { Proponha uma agenda. } \\
\text { Explicar as diretrizes de formalidade da rede de } \\
\text { treinamento }\end{array}$ & $\begin{array}{l}\text { Abra a discussão. } \\
\text { Esclareça o tópico da discussão. } \\
\text { Formule os argumentos iniciais. }\end{array}$ \\
\hline $\begin{array}{l}\text { Supervisão / } \\
\text { Monitoramento }\end{array}$ & $\begin{array}{l}\text { Incentive e incentive a participação regular. } \\
\text { Reconhecer o grupo como uma entidade em seu } \\
\text { próprio direito para criar sinergia entre os } \\
\text { participantes. }\end{array}$ & $\begin{array}{l}\text { Reconheça e incentive o feedback dos } \\
\text { colegas. } \\
\text { Convide seus colegas para participar } \\
\text { regularmente. }\end{array}$ \\
\hline $\begin{array}{l}\text { Malha de } \\
\text { discussão }\end{array}$ & $\begin{array}{l}\text { Extraia e destaque os principais tópicos da } \\
\text { discussão. } \\
\text { Feche a discussão com um resumo. }\end{array}$ & $\begin{array}{l}\text { Gerenciar a sobrecarga de } \\
\text { informações quando a discussão fica } \\
\text { confusa. } \\
\text { Tente extrair e destacar as conexões } \\
\text { entre as ideias. Tente resolver } \\
\text { problemas de compreensão do } \\
\text { conteúdo, clareza e relevância. } \\
\text { Participe do resumo de encerramento. }\end{array}$ \\
\hline
\end{tabular}

Garavit, J. 2021.

\section{Entre a relação e o produto do grupo}

Coesão e produtividade são duas condições que devem ser atendidas para uma colaboração bem-sucedida. Como mostraremos, eles estão intimamente relacionados. Eles estão imbuídos de subjetividade e só podem ser medidos por meio das percepções dos alunos. A coesão é um sentimento extremamente positivo que reina dentro de um grupo e se expressa por meio de um comportamento de apoio e da participação regular dos membros. A produtividade se refere às impressões que se espalham para os membros de um grupo quando suas interações levam a uma produção que eles consideram satisfatória. Portanto, a coesão e a sensação de ser produtivo são, para um grupo, indicadores de maturidade. Em geral, Um grupo passa por estágios de crescimento e desenvolvimento que o levam à maturidade quando seus integrantes se tornam bons colaboradores. Eles se conhecem bem, sabem interagir e desenvolveram um senso de pertencimento.

A coesão não existe sem formar um grupo real. É feito de solidariedade e auto-regulação. É a consequência dos impulsos que operam nos membros para encorajá-los a permanecer juntos. A coesão aumenta sua força quando os membros concebem certo gosto pelo grupo e têm um forte desejo de pertencer a ele; essa é a atração do grupo. $\mathrm{O}$ grau de proximidade e a identificação dos membros do grupo também são forças coesivas. A coesão serve como índice de maturidade do grupo e, se for forte, afeta positivamente a produtividade. Em um grupo, o grau de coesão e o nível de produtividade influenciam-se mutuamente em uma correlação positiva. 
A produtividade se manifesta na eficácia e facilidade do grupo para chegar a um acordo sobre um objetivo comum, desenvolver um plano de trabalho, implementá-lo, revisá-lo ao longo do caminho e realizar bem sua atividade. Não existe uma medida objetiva para avaliar a produtividade de um grupo. As escalas são tão numerosas quanto os próprios grupos. Os resultados obtidos são sempre subjetivos, pois refletem percepções de satisfação sobre a eficácia que o grupo tem demonstrado em estudar uma questão, resolver o problema, tomar decisões, realizar uma atividade, etc. Ao promover a interdependência positiva entre os alunos, o treinador pode estimular a coesão e aumentar a produtividade. Você pode medir a qualidade das interações e o conteúdo cognitivo das mensagens.

\section{Estruture o espaço de comunicação}

Conforme explicado acima, a comunicação é o coração da colaboração e, como resultado, o espaço de comunicação ocupa um lugar central no ambiente de aprendizagem. Para o designer pedagógico, a estruturação deste espaço é um passo eminentemente importante, pois será decisivo para o sucesso de uma colaboração. Devido ao seu posicionamento estratégico, o espaço de comunicação deve ser cuidadosamente organizado de acordo com a tarefa de aprendizagem e as atividades das quais os alunos irão participar. Para entender melhor como funciona a colaboração, é importante esclarecer aqui a distinção que fazemos entre a tarefa de aprendizagem que é feita individualmente e as atividades de suporte à aprendizagem que são feitas em grupos ou em equipes.

Mencionamos que existe um grupo colaborativo para um objetivo comum compartilhado por todos. Em um contexto de treinamento, cada aluno que faz parte de um grupo visa atingir o objetivo por meio do desempenho individual de uma tarefa de aprendizagem. Além disso, os alunos são convidados a realizar atividades em grupo ou em equipe que os ajudarão a realizar a tarefa individual. É assim que o grupo atua como recurso e suporte para a formação tende a mudar em um lugar de ajuda mútua e colaboração. Por exemplo, se a tarefa é produzir uma análise das tensões ideológicas em nossa sociedade por meio da doutrina econômica, o designer pode organizar uma grande atividade do tipo "debate" sobre os méritos da abordagem econômica.

Ao se preparar para isso por meio de leituras, pesquisa documental e discussões em equipe, os alunos serão capazes de reconhecer os prós e os contras e debater o tópico de forma convincente no âmbito de um fórum de discussão que reúne todos os alunos do grupo. Estas atividades de investigação, discussão e debate permitirão aos alunos recolher informações, refletir sobre a questão levantada e analisar as diferentes posições. No seu espaço privado, o aluno prepara-se para a realização de atividades em grupo ou equipa que, por sua vez, decorrem no espaço de comunicação. Porém, o aluno poderá apresentar 
informações, negociar suas ideias com o grupo e validar os conhecimentos adquiridos. Você então retornará ao seu espaço individual para completar o

conclusão da tarefa de aprendizagem. Portanto, o espaço de comunicação deve ser organizado em locais diferentes para:

- Discuta em um grande grupo,

- Coordenar a execução das atividades coletivas,

- Realizar atividades em equipe,

- Encontre ajuda,

- Colabore espontaneamente,

- Socializar,

\section{Construção do conhecimento coletivo}

Você pode propor o uso de fóruns eletrônicos, organizando-os em locais de:

- Gerenciamento remoto, coordene o processo colaborativo.

- Discussão tele.

- Teletrabalho para as posições habituais de conhecimento e para o avanço coletivo de novos conhecimentos.

- Tele socialização, canal de trocas informais e espontâneas.

- Assistência remota, para aconselhamento e suporte técnico.

A Figura 2.4 mostra a disposição dos locais para intercâmbio, trabalho e aprendizagem.

Figura 2.4

Desenvolvimento de intercâmbio no local de trabalho

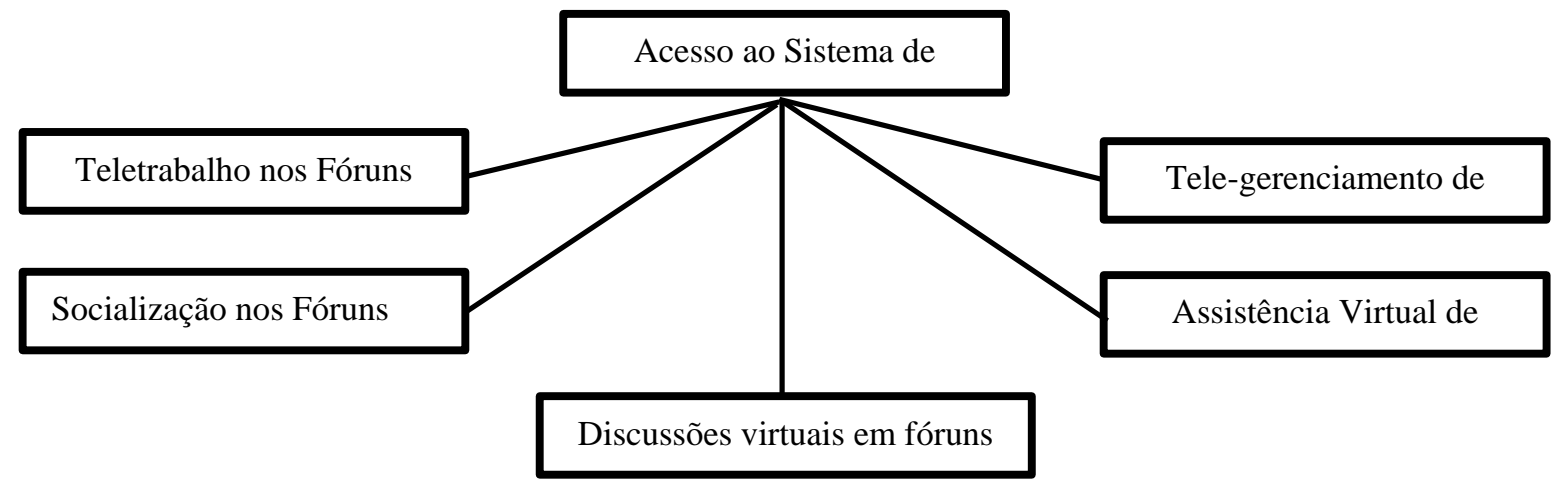

Garavit, J. 2021 


\section{Início de uma gestão remota}

Os fóruns de telegestão são locais onde as atividades do grupo são coordenadas (ver figura 2.5); eles constituem um centro de organização e gestão educacional, cognitiva e logística. Os alunos se reúnem ali para definir um plano de trabalho, pactuar um cronograma, cuidar da organização temporal e material das atividades, formar equipes, discutir as orientações cognitivas do trabalho, negociar, determinar o modo de participação e determinar a contribuição e o papel de cada um. Idealmente, os alunos devem ter acesso a ferramentas de planejamento, monitoramento do trabalho e suporte à decisão para facilitar o trabalho de gerenciamento. Os locais de telegestão são os mais propícios para concordar explicitamente sobre os termos de colaboração,

Figura 2.5

Gerenciamento remoto

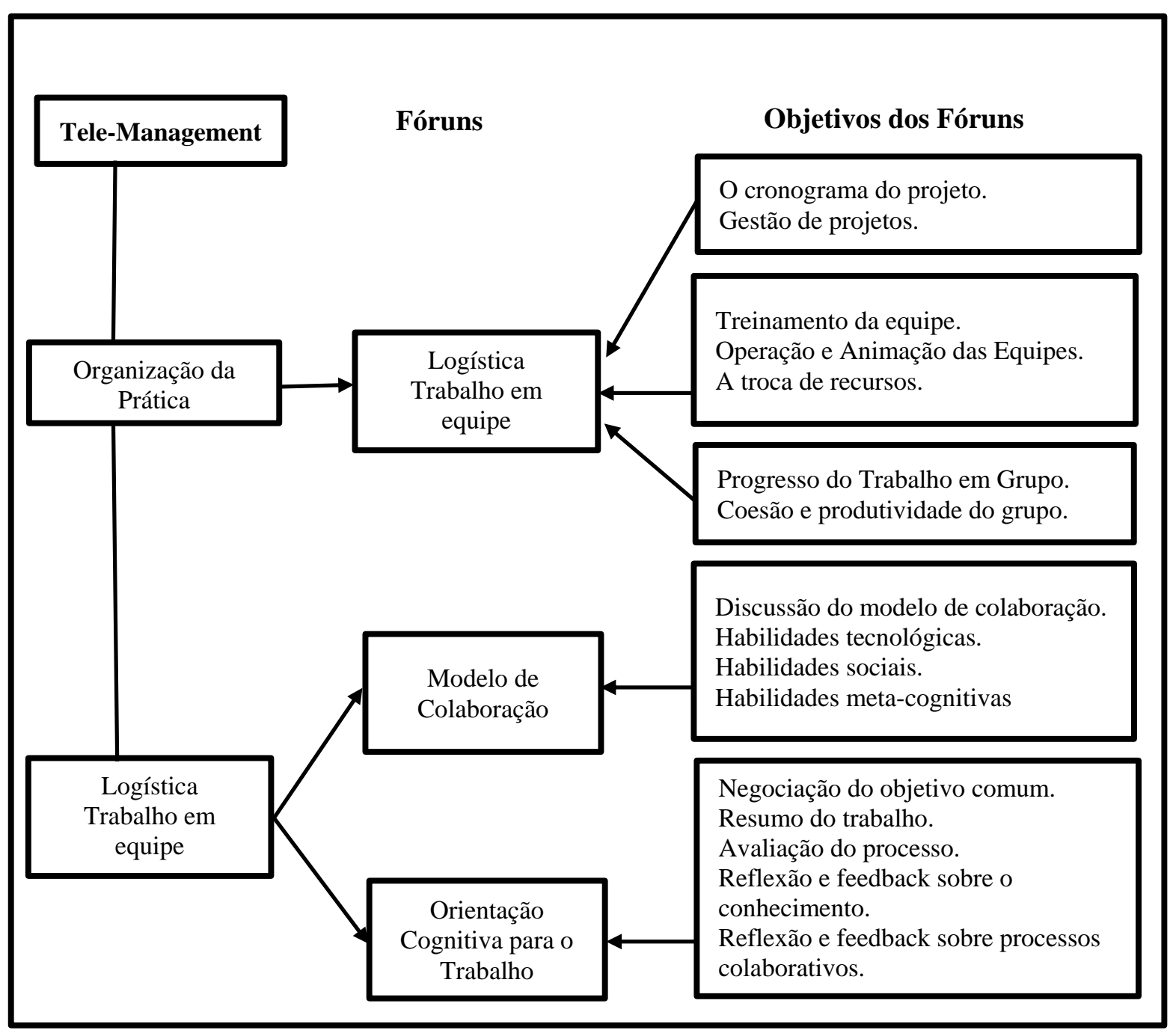

Garavit, J. 2021 
Os alunos que conhecem os requisitos da colaboração são convidados a inscrever-se voluntariamente e a cumpri-la com pleno conhecimento dos factos. Ao mesmo tempo, eles são incentivados a compreender os objetivos de aprendizagem e dar sentido às atividades colaborativas. Os alunos que compartilham a mesma representação de colaboração são mais propensos a respeitar o modus operandi e ter sucesso em sua colaboração.

Os métodos colaborativos e a orientação cognitiva do trabalho nem sempre são objeto de discussão em grupos aos quais é oferecida uma abordagem coletiva. Surpreendidos pelas demandas de colaboração, os alunos podem apresentar frustração, insatisfação e desmotivação que podem levá-los a desistir ou ser a causa do insucesso da atividade formativa. Para evitar mal-entendidos sobre os requisitos da colaboração e otimizar seu sucesso, o grupo deve reservar um tempo para discutir as condições e chegar a um acordo sobre o modelo de colaboração que prevalecerá.

Além de serem espaços de discussão do modelo de colaboração e dos aspectos práticos da organização do grupo, os fóruns de telegestão também são locais onde o grupo estabelece um consenso sobre a orientação cognitiva que deve ser dada ao trabalho e onde o objetivo comum é com a assinatura de alcançar.

Figura 2.6 - Tele-discussão

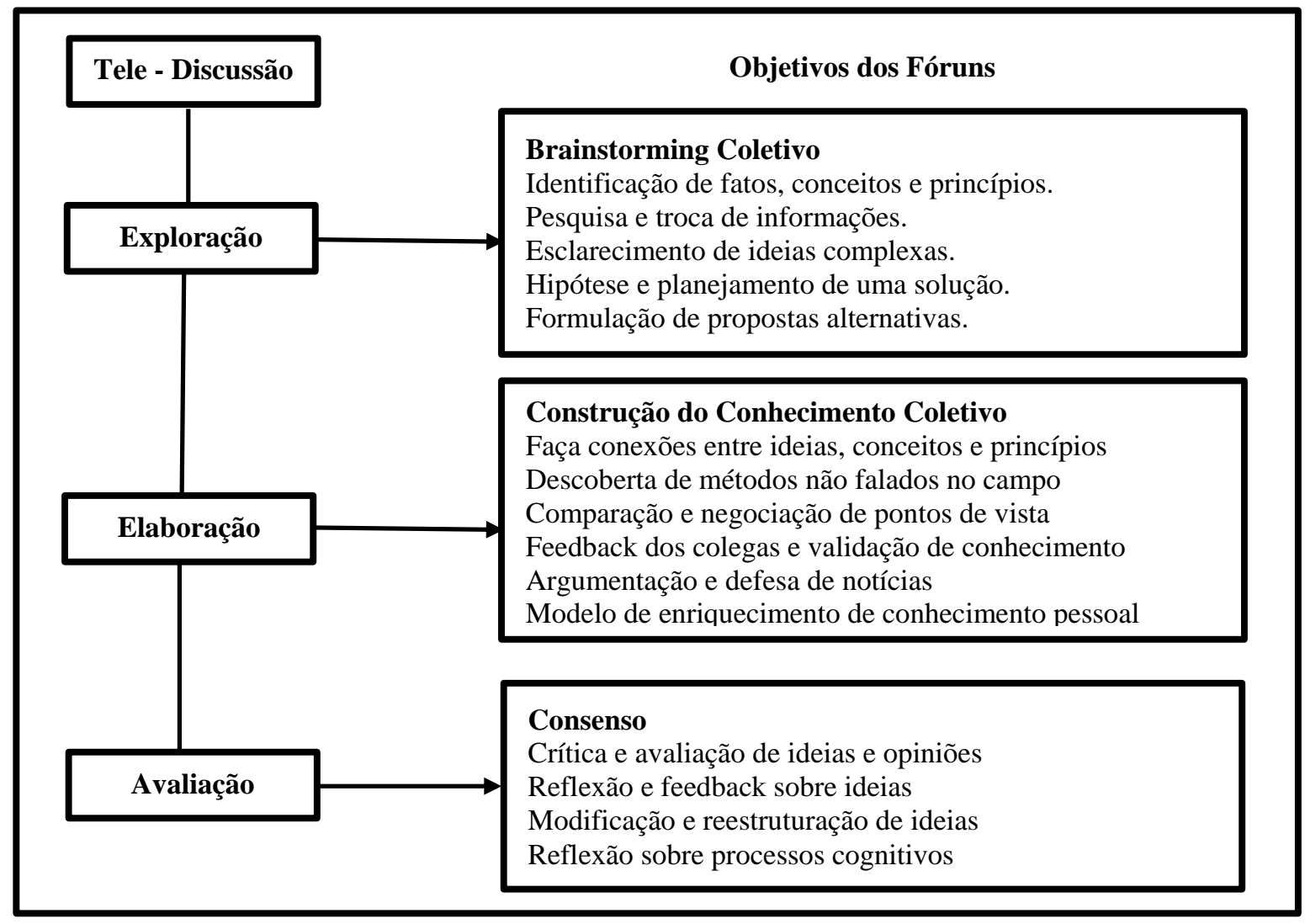

Garavit, J. 2021 


\section{Tele-discussão}

Os fóruns de tele-discussão são locais privilegiados para explorar conceitos por meio da argumentação, desenvolvimento e avaliação do conhecimento por meio do diálogo e da interação (ver figura 2.6). Eles oferecem a oportunidade de bater um papo, fazer perguntas e resolver problemas. Eles são para os participantes a fonte de enriquecimento cognitivo. Porém, já havia sido notada a força e a sinergia dentro dos grupos de trabalho intelectual, que, por meio da tele-discussão, produzem desempenhos superiores aos que cada membro do grupo pode alcançar. A tele-discussão oferece aos alunos espaços para a construção coletiva do conhecimento, promovendo trocas profundas e reflexivas. De forma prática, os fóruns de Tele Discussão podem hospedar intercâmbios de pequenos grupos de 0 a 5 alunos,

\section{Teletrabalho}

Os espaços de teletrabalho são reservados a equipas de três a cinco alunos para a realização de atividades específicas que antecedem ou prolongam o trabalho realizado em privado ou por tele-discussão. Este trabalho pode ser realizado dentro do próprio fórum de teletrabalho (por exemplo: elaboração de uma definição, troca de informações sobre um tema específico, análise de caso, resolução de problemas, etc.) ou no exterior (por exemplo: constituição de um depósito, redação de um ensaio, desenvolvimento de um programa de computador, etc.). No primeiro caso, o fórum de teletrabalho é o local utilizado para o planejamento, organização e execução efetiva da atividade. Caso o projeto deva ser realizado fora do fórum em um espaço privado, como seria o caso de um projeto de programação, por exemplo, As discussões no fórum de teletrabalho se concentrarão no planejamento e avaliação do projeto. o ambiente de aprendizagem (ver Figura 2.7)

Figura 2.7 - Tele-trabalho

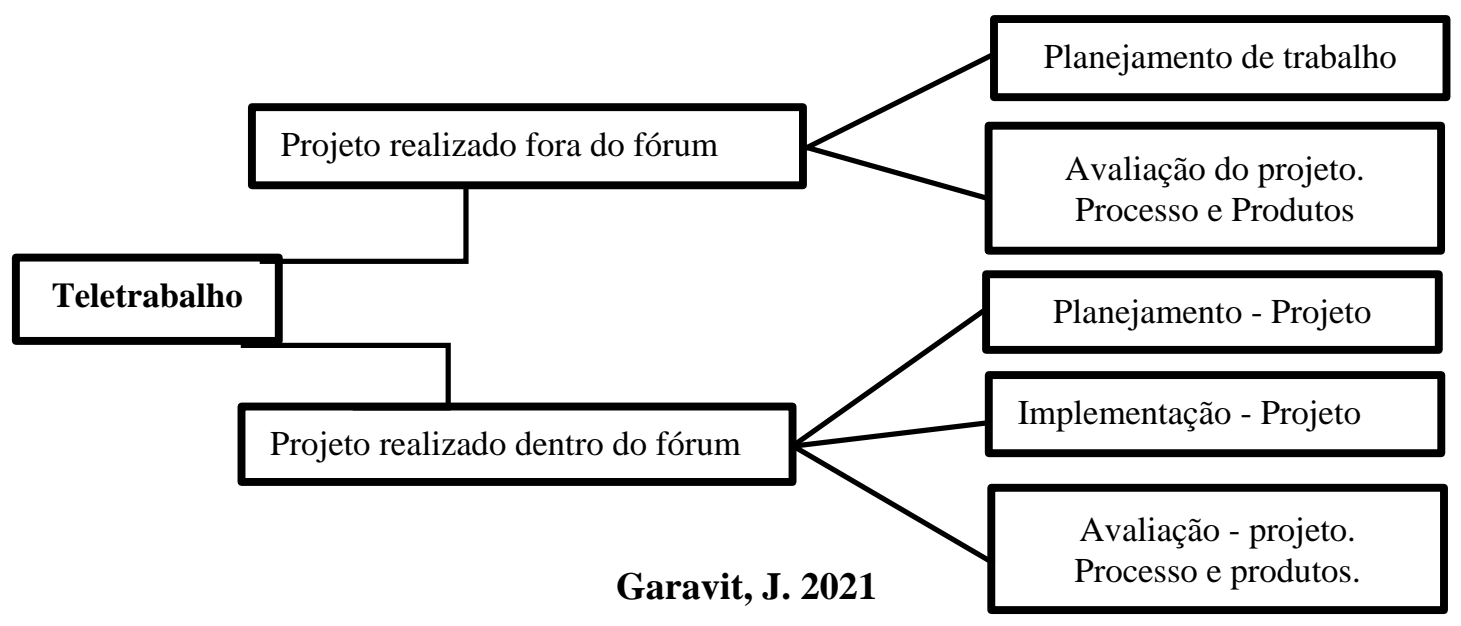


Além disso, dependendo das atividades a serem desenvolvidas, os fóruns de teletrabalho podem servir de local de incubação e planejamento das conversas ou discussões que ocorrem na tele-discussão. Eles podem ser usados para fragmentar grandes grupos e, assim, otimizar as trocas, evitando a sobrecarga ou subcarga de informações. Devido ao pequeno número de participantes, os fóruns de teletrabalho representam locais mais íntimos e menos ameaçadores, onde os alunos podem expressar livremente suas ideias e opiniões antes de compartilhá-las em uma teletrabalho. Como as atividades que acontecem nos fóruns de teletrabalho são mais circunscritas e muitas vezes mais específicas, é mais fácil participar porque as trocas são mais diretas. Os fóruns de teletrabalho podem servir como um local adequado para alunos que são novos em fóruns e comunicação assíncrona. Tanto quanto possível, a facilitação desses fóruns deve ser deixada para os alunos que, ao aprenderem a se dirigir, desenvolverão sua liderança e autonomia.

\section{Socialização remota}

Em um ambiente virtual de aprendizagem, devemos levar em consideração um conjunto de necessidades que afetam a aprendizagem: cognitivas, mas também emocionais e psicossociais. Destes, a socialização e a necessidade de se comunicar informalmente não podem ser ignoradas. São necessidades universais que não param de se expressar nas comunidades virtuais. Em ambientes onde não há lugar ou meios para satisfazer a necessidade de socialização, os participantes sempre tentam preenchê-la, o que às vezes resulta em caos. Eles podem sequestrar o propósito original de um fórum instalando-o em um local de troca informal. Pudemos observar em diversas ocasiões fóruns que perderam o interesse e a credibilidade porque os participantes, buscando o convívio,

Portanto, os fóruns de telessocialização têm a função de canalizar trocas informais e espontâneas que não cabem nos fóruns de telegestão, teletrabalho ou tele-discussão. Eles promovem a criação de um espírito de grupo e o desenvolvimento de pertencimento. As intervenções de um moderador sempre têm seu lugar nesses tipos de fóruns. Sem realmente enquadrar a discussão, ele observa o tom e o clima das discussões e garante que boas relações sejam estabelecidas entre os participantes. Certifique-se de que o fórum de tele-socialização incentiva a colaboração. Se necessário, você pode intervir com autoridade para impor o respeito pelos outros e condenar qualquer falta de ética. Em alguns grupos, o moderador de um fórum de tele-socialização pode, sem dúvida, ser um estudante. 


\section{Figura 2.8 - Socialização remota}

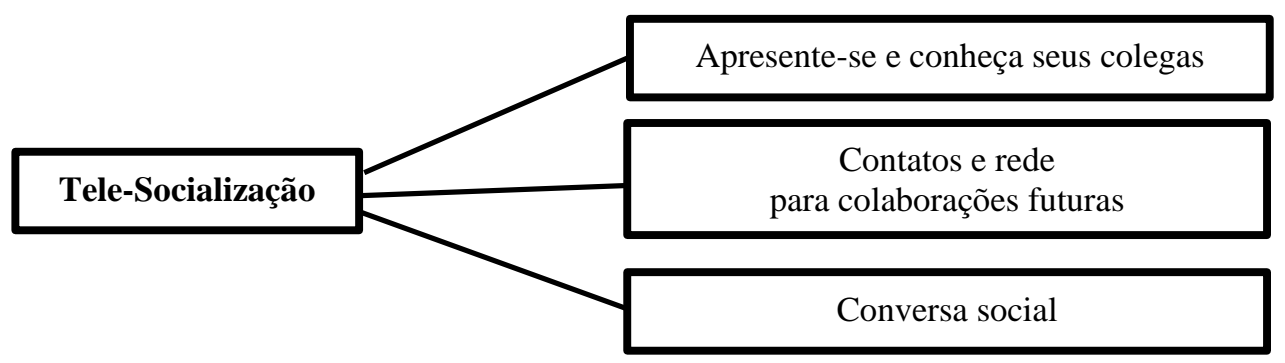

Garavit, J. 2021

Assim como nos campi tradicionais são reservados locais de encontro informais, salões, salas de recreação, refeitórios, locais de relaxamento, etc., os locais de socialização devem ser configurados no ambiente virtual (ver figura 2.8 ).

\section{Figura 2.9 - Assistência remota}

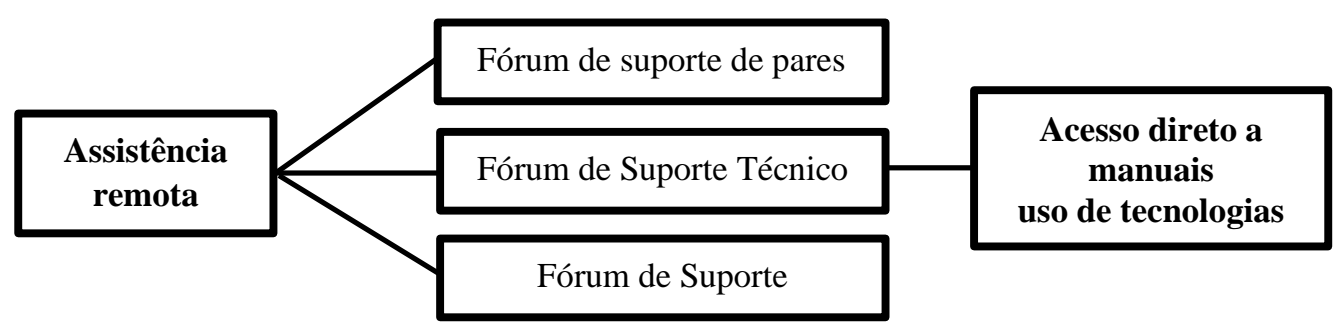

Garavit, J. 2021

\section{Colaboração remota}

Os fóruns de teleatendimento (Figura 2.9) oferecem assistência aos alunos com problemas técnicos ou administrativos. Os moderadores desses fóruns garantirão que as solicitações expressas sejam respondidas, caso eles próprios não possam respondê-las. Como os anteriores, sua função é receber comentários que não cabem nos fóruns de telegestão, teletrabalho ou tele discussão.

\section{Estrutura própria e flexível}

A estrutura do espaço de comunicação que acabamos de descrever servirá como um ponto de referência para o designer de ambientes de aprendizagem. Propõe lugares genéricos que organizará e organizará de acordo com a tarefa de aprendizagem e as atividades colaborativas que proporá ao grupo. O designer cuidará de uma organização ergonômica e amigável. A experiência tem mostrado que os fóruns de discussão não devem ser muito numerosos, pois 
corre-se o risco de confundir o aluno que pode se perder no labirinto dos fóruns, sem saber onde ir para postar sua mensagem, ou mesmo deixá-la e ir para vários lugares e participar de muitas discussões.

Quantos fóruns, sobre quais assuntos, para participar de quais atividades, em quanto tempo? As respostas virão de uma abordagem de engenharia baseada na análise do conteúdo e da estrutura da tarefa de aprendizagem e das atividades selecionadas. Ansioso por estar aberto às necessidades dos formandos, o designer terá proporcionado ao formador e até aos formandos a capacidade de criar novos locais durante a formação. Terá deixado o campo aberto à criação de espaços emergentes para acolher colaborações espontâneas, mais ou menos formais, para responder a uma necessidade e apoiar o processo colaborativo. 


\section{Referências}

Berge, Z. (1995). Facilitação de conferências por computador: recomendações de campo. Tecnologia Educacional.

Bordeleau, Pierre (1994). Aprenda em ambientes educacionais computadorizados. Montreal, Quebec), Logical Editions.

Bouton, C. e Garth, RY (1983). Alunos em grupos de aprendizagem. Aprendizagem ativa por meio de conversas. Bouton, C. e Garth, RY, Group Learning: New Directions in Teaching and Learning. São Francisco.

Briggs, LJ (1981). Desenho instrucional: princípios e aplicações. Inglewood Cliff, NJ, Publicações de Tecnologia Educacional.

Burge, E. (1994). Aprendizagem em contextos de conferência por computador: a perspectiva do aluno. Journal of Distance Education.

Davie, LE e Wells, R. (1991). Capacite o aluno por meio da comunicação mediada por computador. The American Journal of Distance Education.

De la Teja, I., Lungrend, K. (1997). Relatório de teste de protótipo global. Montreal, centro de pesquisa LICEF, Tele-University.

Dick, W. e Carey, L. (1985). O projeto sistemático de instrução. Glenview. Scott, Forestan and Company.

Dimock, HG (1987). Projetar e facilitar programas de treinamento. 4 ed. University of Guelph.

Donovan, DC (1995). Comunicação mediada por computador e curso básico de fala. Computação e tecnologia interpessoal: uma revista eletrônica para o século 21.

Doré, S. e Basque, J. (1998). "O conceito de ambiente de aprendizagem baseado em computador". Revista de educação a distância.

Duning, BS (1993). Chegar aos alunos através das telecomunicações: estratégias de gestão e liderança para o ensino superior. San Francisco, Jossey - Editores de baixo.

Eales, JRT et Welsh, J. (1996). Design para aprendizagem colaborativa. Austrália, Departamento de Ciência da Computação, Universidade de Queensland e CRC para Tecnologia de Sistemas Distribuídos.

Edelson, DC, O'Neill, DK, Bomez, LM et D'amico, L. (1996). Um projeto para pesquisa eficaz e suporte de colaboração. Escola de Educação e Política Social, Northwestern University, Estados Unidos.

Feenberg, A. (2007). O mundo escrito. Mindweave, comunicação, informática e educação a distância. Dans Robin Mason e Anthony Kaye, Oxford, Reino Unido.

Fraase, M. (1991). Software colaborativo para Macintosh. Um guia completo para computação colaborativa. Log House, Illinois, Richard D. Irwin, Inc.

Fisher, G. (1995). Cognição distribuída, sites de aprendizagem e ambientes de design orientado a domínio. 
Gagné, RM (1985). As condições de aprendizagem. 4a edição, New York, Holt Rinehart e Winston.

Garavit, J. (2017) projeto de um objeto virtual de aprendizagem na UNAD, para fortalecer os processos de aprendizagem do curso de Lógica Matemática na modalidade a distância. https://doi.org/10.13140/RG.2.2.35320.39687

Garavit, J. (2021e). Livro de Métodos Interativos para Educação: Transformando a América Latina na Era Digital, Págs. 277-329 ISBN: 978-958-49-2799-6.

Gunawardena, CN (1991a). Tendências atuais no uso de tecnologias de comunicação para a oferta de educação a distância. Revista Internacional de Mídia Educacional.

Gunawardena, CN (1991b). Mudar os papéis dos professores para a audiografia e o ensino online ». The American Journal of Distance Education.

Guzdial, M., Turns, J., Rappin, N. e Carlson, D. (1995). Suporte colaborativo para aprendizagem em domínios complexos.

Harasim, L. (1990). Educação online. Perspectivas de um novo ambiente. Nova York, Praga.

Hiltz, SR (1987). Avaliação da sala de aula virtual. Livro Branco do CCCC, Centro de Conferências e Comunicações Computadorizadas, Instituto de Tecnologia de Nova Jersey, Newark, NJ

Laurillard, D. (1995). A multimídia e a mudança de experiência do aluno. British Journal of Educational Technology.

Lemke, JL (1994). Discurso, dinâmica e mudança social. Halliday, MAK, Dynamics. Papel dinâmico, disponível por FTP.

Linard, M. (1995). Novos debates sobre suporte à aprendizagem. Revista de Aprendizagem Assistida por Computador.

Mager, RF (1962). Elaboração de objetivos instrucionais. Palo Alto, Cal.

Mason, R. (1993). Conferência por computador: The Last Word UK, Beach Holme Editors.

Morlan, John E. (1973). Centros de aprendizagem em sala de aula: planejamento, organização, materiais e atividades. Belmont, Cal.

Pugh, SL (1993). Uso de estudos de caso e comunicação colaborativa auxiliada por computador para apoiar a aprendizagem conceitual em um curso de formação de professores em leitura crítica. ' Tecnologia Educacional.

Romiszowski, AJ (1980), Instructional Systems Design, Londres - Kogan Page.

Rowntree, D. (1995). Ensino e aprendizagem online: educação por correspondência para o século 21? British Journal of Educational Technology.

Salomón, G. (1992) O que significa um design CSCL eficaz? exigem e como estudamos seus efeitos? SIGA o Outlook.

Shedletsky, L. (1993). Mente da comunicação mediada por computador: CMC como aprendizagem experiencial. Tecnologia Educacional.

Schragé, M. (1990). Mentes compartilhadas. Novas tecnologias de colaboração. Nova York, Random House.

St-Arnaud, Y. (1989). Pequenos grupos. Participação e comunicação. Montreal, Imprensa da Universidade de Montreal, Les Éditions de CMI. 
Steeples, C., Goodyear, P. e Mellar, H. (1994). Aprendizagem flexível no ensino superior: o uso de comunicações por computador. Computadores na educação.

Suthers, D. e Weiner, A. (1995). Artigos em grupo para desenvolver habilidades de discussão crítica. 